\title{
2.3 Comprehensive environmentally safe water treatment technologies
}

\section{Techno-economic feasibility for water purification from copper ions}

Nowadays, the stock of fresh water for human needs are insignificant and exhaustive in many places around the globe. In different parts of the planet, fresh water supplies are absent or insufficient for agricultural, industrial, drinking and other household needs. More and more enterprises are focusing on the highly efficient schemes of water consumption. In the chemical industry, during manufacturing of galvanic elements, leather and fur products, printing, the release of heavy metal ions takes place [139-142].

The implementation of environmentally unreliable technologies in industry processes leads to increase in the content of different pollutants, including heavy metal ions, in wastewater. Ions of iron, cadmium, copper, chromium, nickel, cobalt, lead, manganese, zinc, molybdenum, mercury, etc. are cost common pollutants of industrial wastewaters. Ions of heavy metals are toxic and carcinogenic. Moreover, unlike organic substances, inorganic elements are not biodegradable and can accumulated in different living organisms. Thus, they have harmful effects ion living organisms causing serious health problems.

Hydrosphere pollution with these pollutants is one of the most serious and urgent problem of our time. Therefore, it is important to conduct research work on wastewater treatment from heavy metal ions to obtain pure water for technical and drinking purposes and to find the most effective methods for the following development of integrated technologies.

For strict control over the discharge of wastewaters into the water objects of the environment, it is necessary to use relatively inexpensive and effective methods of heavy metals removal. It is important to obtain a significant reduction in the discharge into water bodies of insufficiently treated wastewater, to create closed production cycles of water supply with the application of schemes for reuse of treated wastewater, to improve deep treatment technologies using more efficient processes and to reconstruct the existing treatment equipment using more efficient devices. 
Today, different mechanical, physical and chemical methods can be used to treat wastewater from heavy metal ions. The implementation of these methods requires the use of special equipment, as well as materials and chemicals. Reagent method, ion exchange process, sorption, electrochemical method and membrane extraction is the most widely used methods for wastewater treatment [143-151].

Currently, the reagent method is most widely spread in treatment plants. This method involves adding of different reagents into the wastewater or sewage effluents, resulting in the transformation of toxic compounds into low-toxic or non-toxic with their further precipitations. $\mathrm{CaCO}_{3}$ can be used as the precipitation reagent. A significant advantage of this process is that the moisture content of the precipitates is much lower (less than 50\%) than during lime neutralization (more than $80 \%$ ). This offers a potential decrease in the amount of sludge during wastewater treatment. However, the disadvantage is that the reagent is chemically stable so it needs to be activated for further use. In addition, for example, activated antigorite and dolomite, as well as mechanochemical activated serpentine and magnetite can be applied.

Ferrite, lime and lime water are widely used to precipitate ions of heavy metals. For example, the application of the ferritization method allows to achieve a high degree of purification, and thus prevents the discharge of contaminated wastewater into natural water reservoirs and reduces water consumption due to the application of treated water in the circulating water supply system. During reagent method, the duration of the process at the temperature above $60^{\circ} \mathrm{C}$ is $20-30$ minutes, lowering the temperature to $30 \mathrm{C}$ leads to prolongation in the duration of the process over one hour. Lime is a quite appropriate reagent, as the reaction of precipitation of copper ions can takes place at normal temperature; thus, there is no need to spend extra energy to heat the solutions. The main disadvantage of reagent methods is the formation of large amount of wet sludge and the absence of the methods for it effective disposal, the need for additional facilities for sludge storage, and that can lead to secondary water pollution.

Copper ions are one of the most common and dangerous pollutants of the water objects of environment. The industrial discharges, also the corrosion of copper pipelines and different constructions are the main sources for water pollution with 
copper ions. It is known that the intake of ions of heavy metals, even in relatively small quantity, reduces immunity, increases susceptibility to infections, affect the development of allergic reactions, autoimmune and cancer diseases. Copper ions also shows immunogenic effect. The increased concentrations of copper adversely affect plant organisms.

In accordance with regulatory documents, the MPC of copper in sanitary water bodies should be no more than $0.1 \mathrm{mg} / \mathrm{dm}^{3}$, in the water of fishery reservoirs is less than $0.001 \mathrm{mg} / \mathrm{dm}^{3}$. Despite the high efficiency of copper removal from water (9999.5\%), the residual concentration of inorganic pollutant in purified water does not always meet the requirements of sanitary standards for discharge of treated wastewater into natural reservoirs for cultural, domestic and other purposes. In this regard, the common technological scheme of wastewater treatment from inorganic pollutants often consists of two processes - reagent treatment and flotation.

\section{Copper ions precipitation as a function of reagent consumption}

Copper sulfate $\left(\mathrm{CuSO}_{4} \cdot 5 \mathrm{H}_{2} \mathrm{O}\right)$ and lime $\left(\mathrm{Ca}(\mathrm{OH})_{2}\right)$ of a.g. were used throughout the experimental work. In order to study the properties of the composites, cement of I500 type (mineralogical composition, wt. \%: $\mathrm{C}_{3} \mathrm{~S}-57,10, \mathrm{C}_{2} \mathrm{~S}-21,27, \mathrm{C}_{3} \mathrm{~A}-6,87$, $\left.\mathrm{C}_{4} \mathrm{AF}-12,19\right)$ was used.

In wastewater, copper can stay in ionic form as well as in the form of complex compounds. In this study, the initial concentration of copper ions in the solution was $1-100 \mathrm{mg} / \mathrm{dm}^{3}$ and $\mathrm{pH}$ was 6.9 .

The most effective removal of copper from aqueous solutions in the form of hydroxides is observed at $\mathrm{pH}$ in the range from 8.5 to 10.0 . The increase in reagent consumption was expected effect the increase of $\mathrm{pH}$.

After reagent treatment, water was left for the period of 60 min for the formation of copper hydroxide and its precipitation. Then the precipitate was filtered and the residual content of copper ions in water solution was determined. The iodometric determination was used for this purpose. The efficiency of copper ions removal was calculated by the formula: 


$$
\mathrm{Z}=\frac{\mathrm{C}_{0}-\mathrm{C}_{\mathrm{f}}}{\mathrm{C}_{0}} \cdot 100, \%
$$

$\mathrm{Z}$ - efficiency of copper ions removal, \%;

$\mathrm{C}_{0}$ - initial copper ions concentration in aqueous solution, $\mathrm{mg} / \mathrm{dm}^{3}$;

$\mathrm{C}_{\mathrm{f}}$ - final concentration copper ions concentration in aqueous solution after reagent treatment, $\mathrm{mg} / \mathrm{dm}^{3}$.

Water treatment from copper ions was carried out according to a statistical $2^{2}$ factorial design and the parameters of the processes are shown in Table 1.

Table 1.

$2^{2}$-factorial design for copper ions precipitation

\begin{tabular}{|l|c|c|c|}
\hline \multirow{2}{*}{ Factor } & \multicolumn{3}{c|}{ Levels } \\
\cline { 2 - 4 } & $(-1)$ & $(1)$ & $(0)$ \\
\hline Initial concentration of copper ions, $\mathrm{mg} / \mathrm{dm}^{3}$ & 2 & 100 & 51 \\
\hline Reagent consumption, $\mathrm{mg-eq} / \mathrm{dm}^{3}$ & 5.4 & 10.0 & 7.7 \\
\hline
\end{tabular}

The variables studied in this work were copper ions initial concentration $\left(\mathrm{X}_{1}\right)$ and reagent consumption during treatment $\left(\mathrm{X}_{2}\right)$.

The model of the technological process can be described by the following secondorder polynomial:

$$
\mathrm{Y}=\mathrm{b}_{0}+\mathrm{b}_{1} \cdot \mathrm{X}_{1}+\mathrm{b}_{2} \cdot \mathrm{X}_{2}+\mathrm{b}_{3} \cdot \mathrm{X}_{1} \cdot \mathrm{X}_{2}+\mathrm{b}_{4} \cdot \mathrm{X}_{12}+\mathrm{b}_{5} \cdot \mathrm{X}_{22}
$$

where $\mathrm{Y}$ is a response factor6 namely efficiency of copper ions removal, \%; $\mathrm{b}_{0}-\mathrm{b}_{1,2,3,4,5}$ are regression coefficients.

The variance analysis was done with application of MINITAB 17 software and the response was built in MATLAB software. All experiments in this study were 
performed three times and the average value was given. The investigations were performed at $20-25^{\circ} \mathrm{C}$.

During the reagent treatment of wastewaters, the inorganic pollutants can be separated from the water solution in the form of precipitates, which can be separated from solution by filtration or centrifugation. Then the purified solution can be discharged into natural water reservoirs or reused in the technological processes.

Lime was used as the reagent for water model solution treatment due to economic reasons, namely price. When lime was added, copper ions precipitated in the form of hydroxides $\left(\mathrm{K}_{\mathrm{sp}}\left(\mathrm{Cu}(\mathrm{OH})_{2} \downarrow\right)=5.6 \cdot 10^{-20}\right.$; solubility $=2.7 \cdot 10^{-6} \mathrm{~mol} / \mathrm{dm}^{3}(0.17 \mathrm{mg}$ $\left.\mathrm{Cu} / \mathrm{dm}^{3}\right)$ :

$$
2 \mathrm{Cu}^{2+}+2 \mathrm{OH}^{-} \rightarrow \mathrm{Cu}(\mathrm{OH})_{2} \downarrow
$$

The application of alkaline reagent raises the $\mathrm{pH}$ of the solution, resulting in reduce of copper ions solubility. At the $\mathrm{pH}$ range from 8.5 to 10.0, copper ions are removed more efficiently and in the form of hydroxides.

The results of the research work at different initial $\mathrm{Cu}^{2+}$ concentration in water solution and lime consumption are shown in Table 2.

Table 2.

Effect of $\mathrm{Cu}^{2+}$ concentration and lime consumption onto removal efficiency

\begin{tabular}{|c|c|c|c|c|c|c|c|}
\hline $\mathrm{X}_{1}$ & 2 & 2 & 2 & 100 & 100 & 100 & 51 \\
\hline $\mathrm{X}_{2}$ & 5,4 & 7,7 & 10,0 & 5,4 & 7,7 & 10 & 7,7 \\
\hline $\mathrm{Y}$ & 99,9 & 99,9 & 99,9 & 46,4 & 73,2 & 99,9 & 92,6 \\
\hline
\end{tabular}

As can be seen from the data in Table 2, the lime consumption has a significant effect on copper ions removal efficiency.

The increase in the efficiency of removal from the aqueous solution with increased consumption of the reagent is connected with an increase of $\mathrm{pH}$, resulting in the formation and precipitation of copper hydroxides. The second-order model of 
normalized variables for factors $\mathrm{X}_{1}$ and $\mathrm{X}_{2}$ (statistically significant coefficients are also given) is the following:

$$
\begin{gathered}
y=101.51-0.9296 \cdot X 1-0.16458 \cdot X 2-0.0025198 \cdot X 1^{2}+0.11868 \cdot X 1 \cdot X 2- \\
0.0047259 \cdot X 2^{2}
\end{gathered}
$$

The model fitted quite well with the experimental data as the $\mathrm{R}^{2}$-value is close to 1. 3D-surface response was also plotted to show the interactions of main effects on efficiency of copper ions removal in detail (Fig. 1).

The higher value of the efficiency of copper ions removal was achieved during the use of lime in the quantity of $10 \mathrm{mg}$-eq $/ \mathrm{dm}^{3}$ of water solution with the concentration of copper ions $100 \mathrm{mg} / \mathrm{dm}^{3}$.

Table 3 shows the optimal values of lime consumption for water treatment with different initial concentrations of copper and the cost of the technology is also shown.

The process of precipitation of copper ions in the form of hydroxide have many advantages such as simple implementation of the technique, low cost, also it is easy to control $\mathrm{pH}$ of the process. However, the main disadvantage is the formation of large volumes of sludge during the treatment, which must be processed.
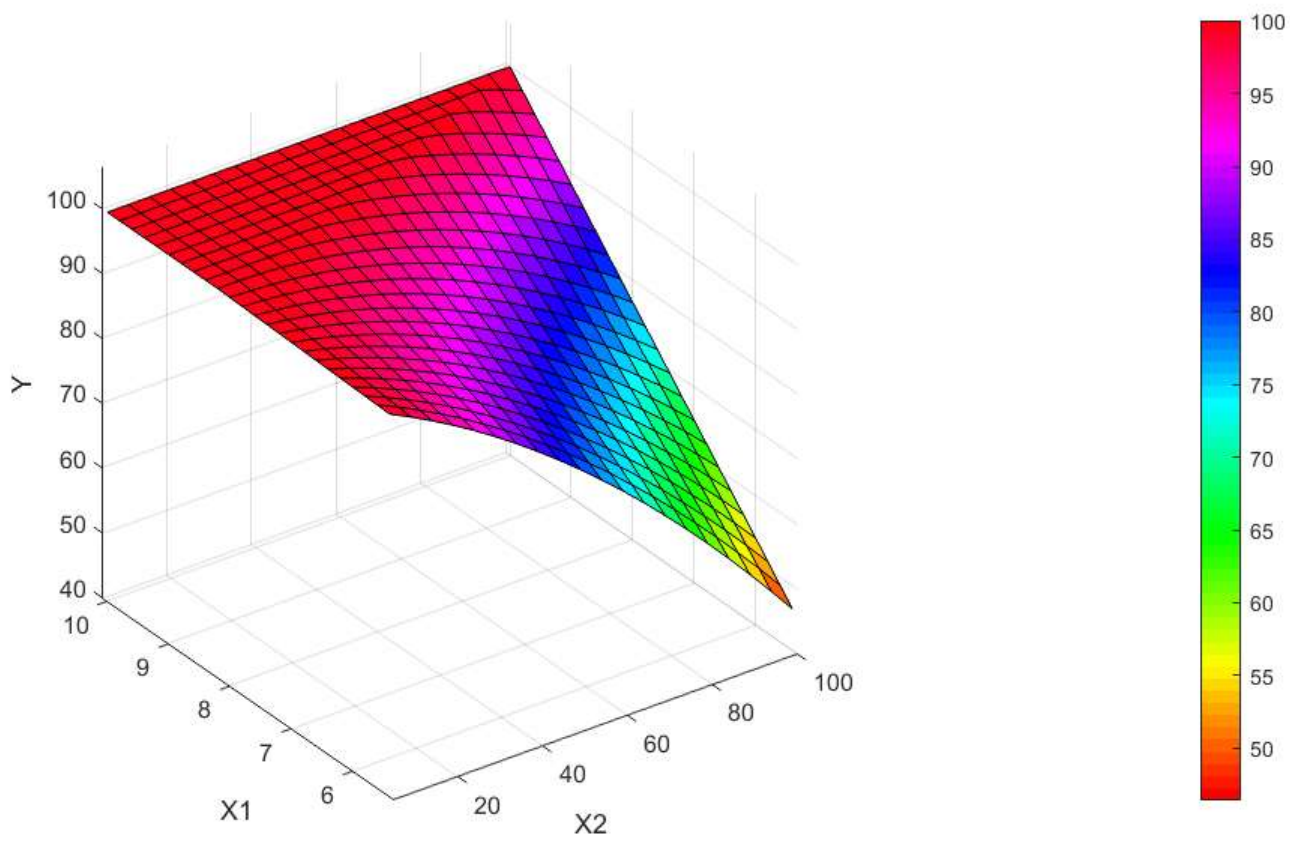

Figure 1.3D-surface response for the efficiency of copper ions removal 
Table 3.

Optimal values of lime consumption for water treatment at different initial concentrations of copper ions

\begin{tabular}{|c|c|c|}
\hline $\begin{array}{c}\text { Concentration of } \mathrm{Cu}^{2+}, \\
\mathrm{mg} / \mathrm{dm}^{3}\end{array}$ & $\begin{array}{c}\text { Lime consumption, } \\
\mathrm{mg} / \mathrm{dm}^{3}\end{array}$ & $\begin{array}{c}\text { Cost of the technology for } \\
\text { water treatment, } \$ / \mathrm{m}^{3}\end{array}$ \\
\hline 1.00 & 4.30 & 41.14 \\
\hline 2.00 & 4.80 & 46.28 \\
\hline 5.00 & 5.40 & 51.42 \\
\hline 10.00 & 6.50 & 61.71 \\
\hline 20.00 & 7.60 & 72.00 \\
\hline 50.00 & 9.20 & 87.42 \\
\hline 100.00 & 10.00 & 95.14 \\
\hline
\end{tabular}

Utilization of sludge afterwaste reagent treatment of water in composition of cement

Reagent method of water purification characterized by the formation of a large amount of sludge, which should be subject to dehydration and drying. Due to this, $\mathrm{Cu}(\mathrm{OH})_{2}$ in a form of solid powder was obtained and used as chemical additive in the composition of cement.

The precipitates were added into the composition of cement in the amount of $0.5-$ $1.5 \mathrm{wt}$ \% by co-mixing of the components in a laboratory ball mill during $10 \mathrm{~min}$. Mechanical and physical properties of cement composites such as normal density, hardening time, the compressive strength and water separation coefficient were studied $[152,153]$.

Today, from an ecological point of view, it is necessary to solve the problem of utilization or practical reuse of various solid wastes of different industries, as well as to improve the recycling and the reuse of liquid wastes of different branches on industry. Therefore, a method of efficient disposal of the formed precipitate $\mathrm{Cu}(\mathrm{OH})_{2}$ in the composition of cements was studied. 
In Ukraine according to the State standards, no more than 5 wt. \% of additives can be applied in the composition of cement. The impact of copper hydroxide, which was formed during reagent water treatment) on the physicochemical properties of cement is presented in Fig. 2-5. The precipitates were introduced into the cement composition in the amount of $0.5,1.0$ and 1.5 wt. $\%$.

As can be seen, copper hydroxide significantly accelerates hardening time. According to the data, copper hydroxide increases the mechanical strength of the cement samples by $8 \%$ after 2 days of hardening and by $27 \%$ after in 28 days of hardening. The normal density of cement and cement samples with different amount of copper hydroxide was $25 \%$. The adding of the salt does not affect the value of this parameter. Similarly, no effect was observed on the coefficient of water removal from the cement slurry.

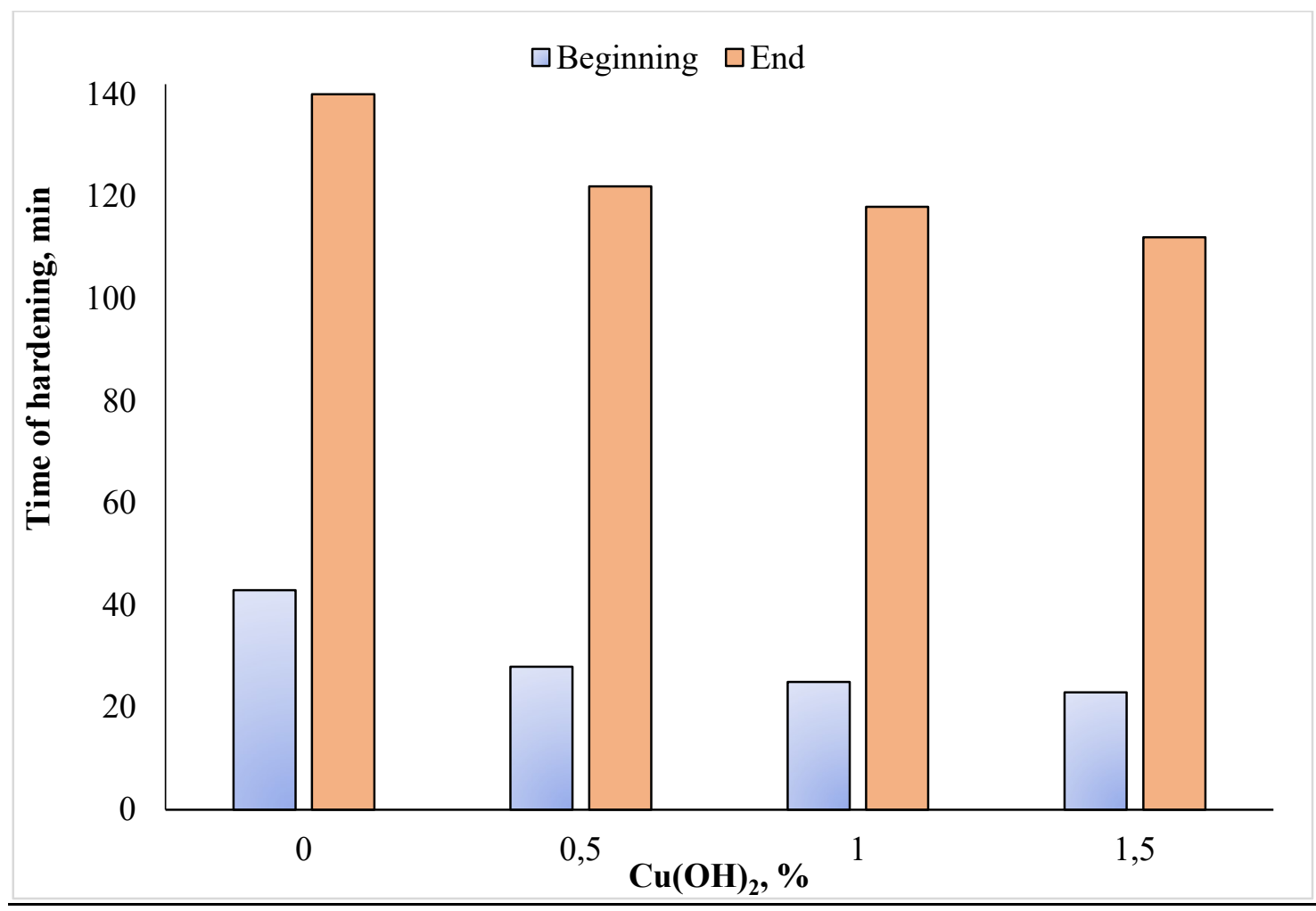

Figure 2. Dependence of hardening time of cement from the consumption of copper hydroxide as an additive 


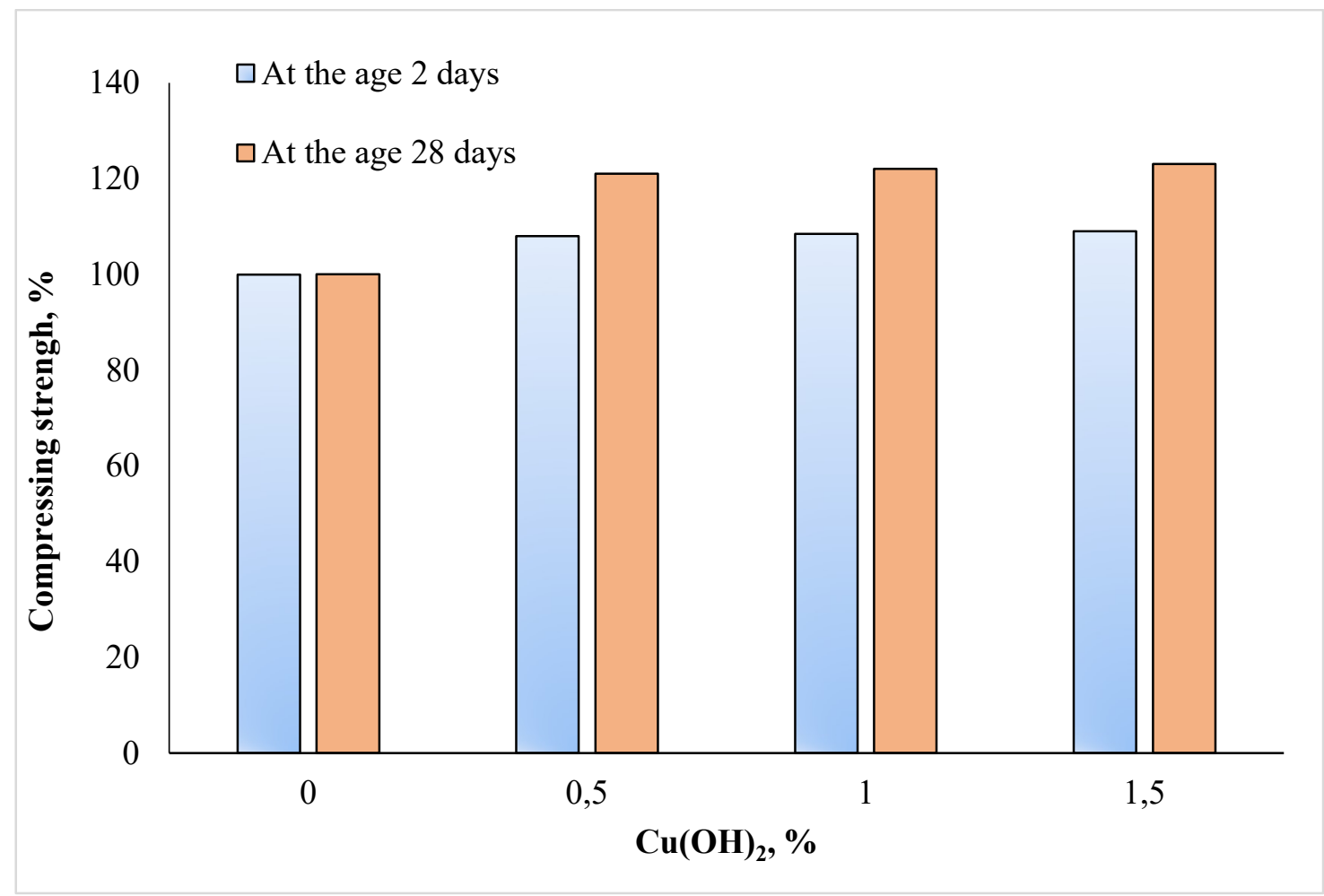

Figure 3. Dependence of compressive strength of cement from the consumption of copper hydroxide as an additive

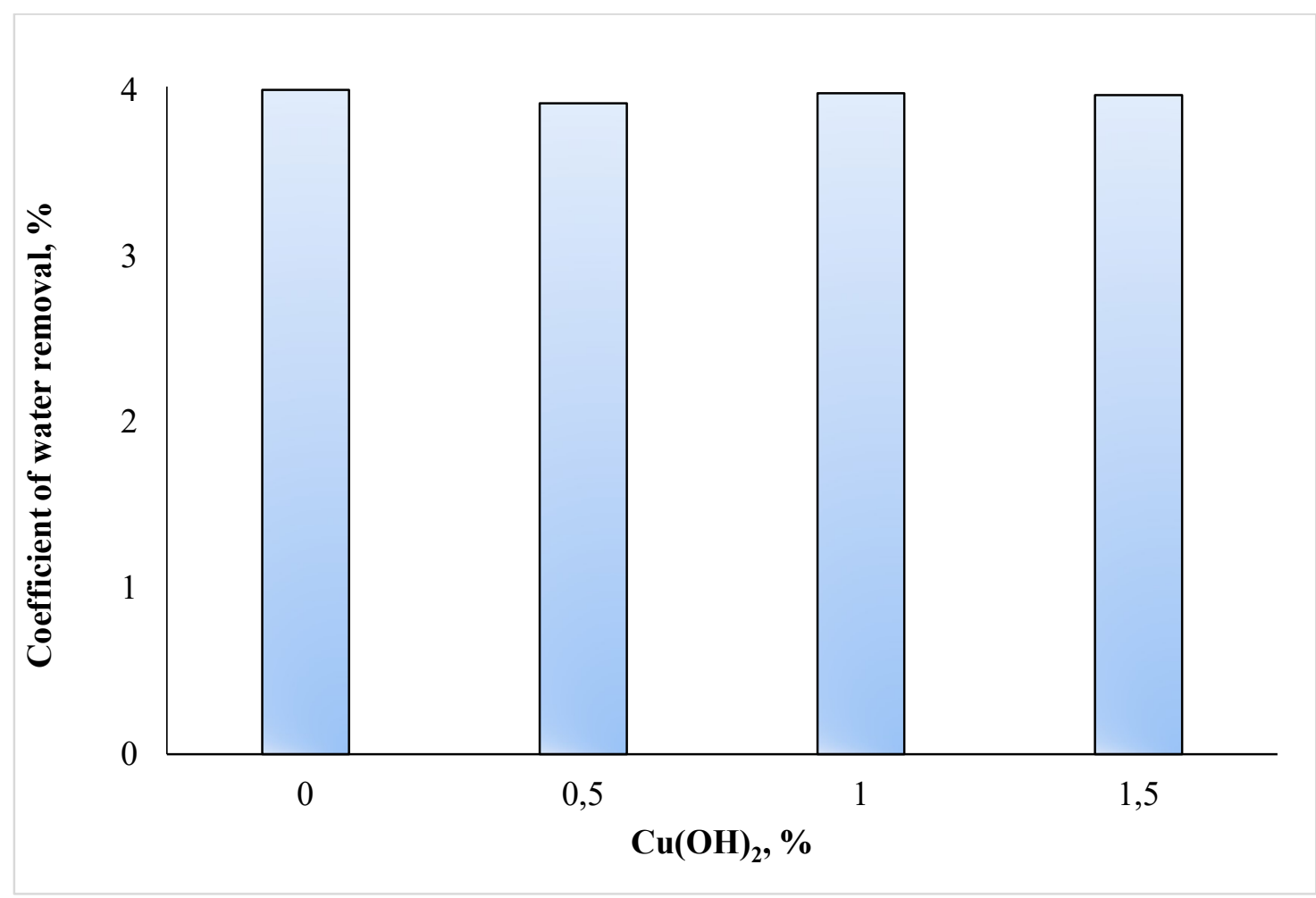

Figure 4. Dependence of coefficient of water removal of cement from the consumption of copper hydroxide as an additive 


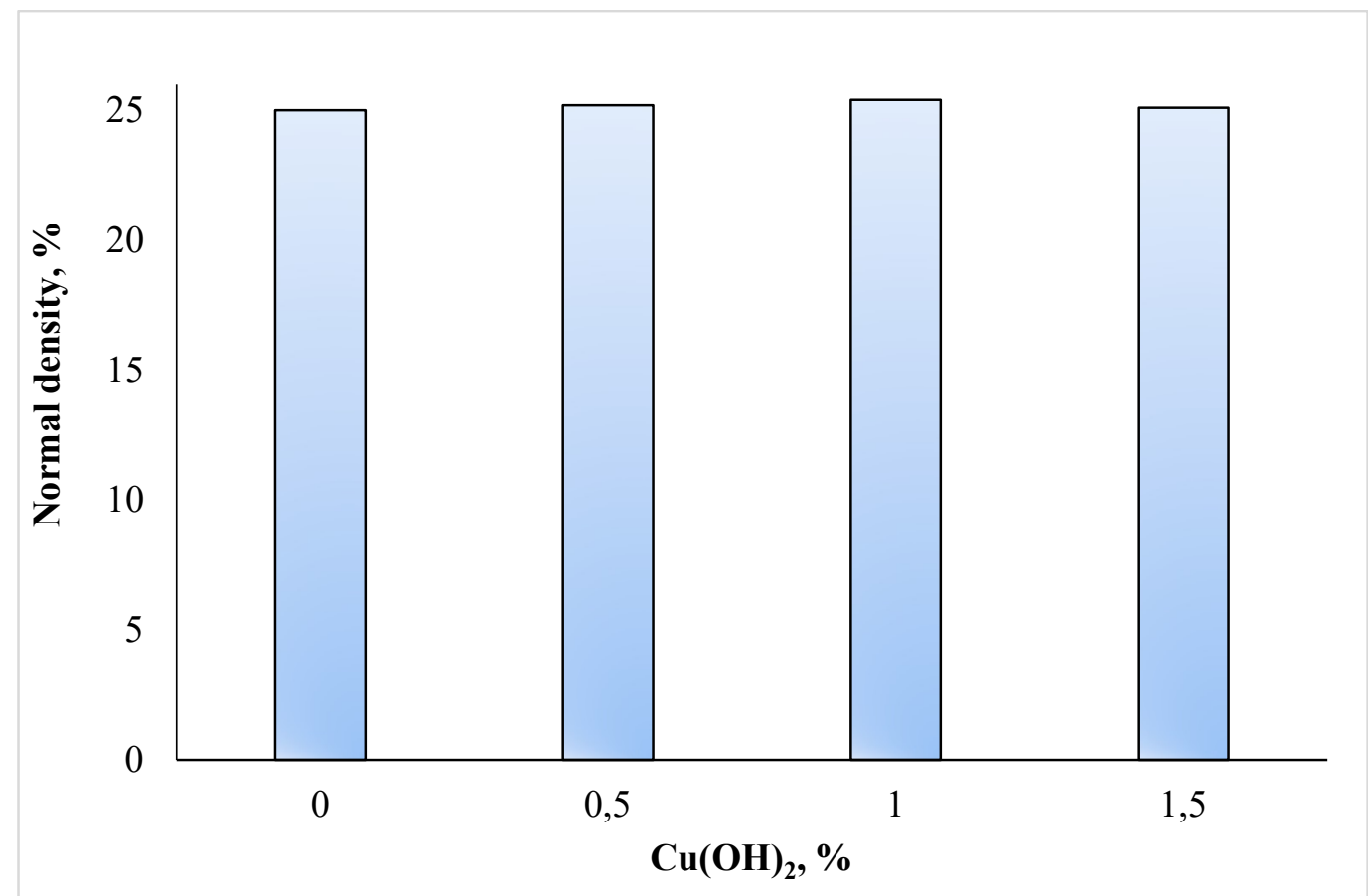

Figure 5. Dependence of normal density of cement from the consumption of copper hydroxide as an additive

Thus, the copper hydroxide precipitate 6 which is formed during the reagent water treatment, can be recommended for the use in the composition of cement as chemical additives that will help to regulate and accelerate the hardening time of cement samples.

The scheme of complex technology for wastewater treatment from copper ions is was developed and is presented in Fig. 6.
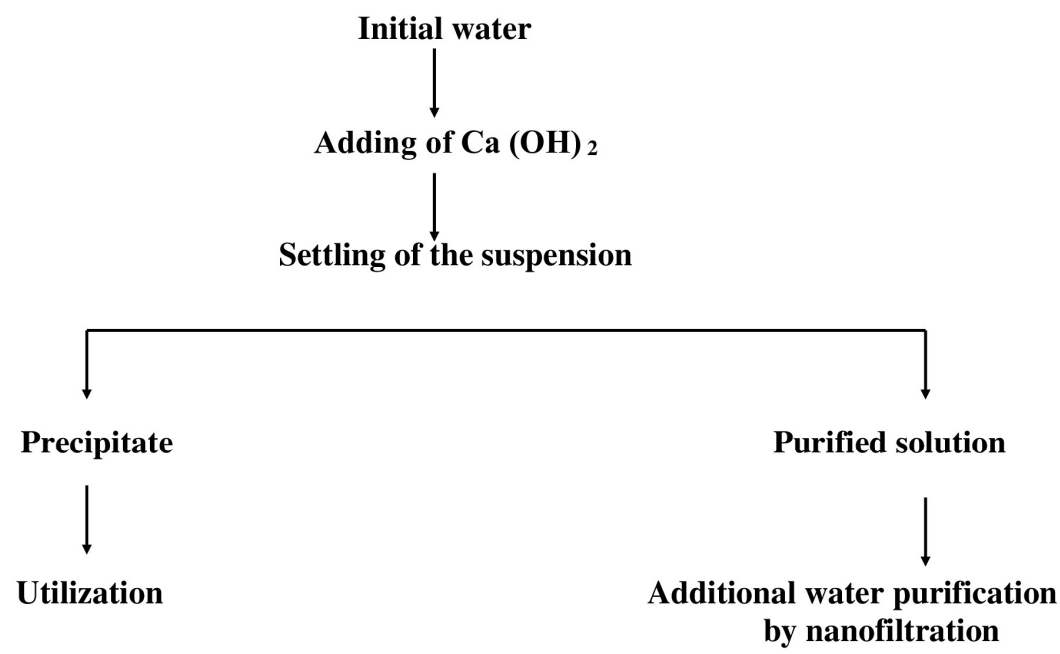

Figure 6. Scheme of complex technology of wastewater treatment from copper ions using reagent method 
After reagent treatment, if necessary, it is possible to apply a subsequent treatment of water on the nanofiltration membrane, which will increase the removal efficiency of $\mathrm{Cu}^{2+}$ ions to $99.6 \%$.

\section{Water treatment with biosorbents}

Today, surface and groundwater are the main sources of fresh water all over the world. So the problem of their preserving is quite urgent. Ukraine is characterized by both qualitative and quantitative depletion of water resources due to their contamination because of the discharge of huge volumes of insufficiently treated wastewater. Heavy metals ions can be discharged into the natural sources with sewages of different production of different branches of industry; can interact with other organic and inorganic compounds of water and can exhibit toxic impact towards living organisms.

High pollution of natural water bodies with mineralized water and toxic compounds requires the development of effective methods to decrease this impact. One of the priority tasks in the field of environmental protection is to find safe and effective wastewater treatment method. For nowadays, sorption, reagent, membrane, electrochemical, ion exchange, biological methods can be used for wastewater treatment from different pollutants.

At present, the urgent problems of utilization of waste from agro-industrial complex, rational use of nature and transition to the use of environment-friendly and energy-efficient technologies are acute. One of the promising directions is the application of principles of "green chemistry", namely the development of technological processes with the application renewable raw materials. In recent decades, publications show that traditional expensive sorbents can be replaced by cheap materials derived from natural raw materials based on lignocellulosic complex, which can be easily modified in different ways. Natural biopolymers of plant origin have a greater number of valuable properties, due to which such materials can be used in chemical, pharmaceutical, food and many others branches of industry. The possibility of the use of renewable raw materials in the production of different materials 
and products for the protection of improvement and for the solution of the ecological problems related to technogenic pollution of water objects by various organic and inorganic toxicants, including radioactive elements, heavy metal ions, petroleum products and other pollutants is of particular interest. It is also necessary and important to use "green" technology both in Ukraine and abroad. Each region is able to choose its own raw material source depending on the specificity of the agro-industrial complex.

Nowadays, to ensure the sustainable development of the agro-industrial complex, the utilization of solid waste of agriculture and food industry should involve use of such wastes as the secondary raw materials for the production of a wide range of materials and products, such as animal feed, fuels, fertilizers, medical and food products. Today, Ukraine is one of the largest exporters of agricultural products to Europe. A large amount of plant wastes is generated each year here. The main method of their utilization is burning. The efficiency of this method is quite low because of the low heat capacity. At the same time the huge impact on environment is observed. From the economic point of view, it is promising to use solid wastes of agro-industrial complex as biosorbents for wastewater treatment [154-163]. Chemical activation and modification of natural plant materials promoted the improvement of their sorption properties for water purification [164-170]. One of the promising ways of utilization of spent biosorbents can be their application in the composition of building materials [171-181].

The purpose of this part of work was to develop the efficient application of biosorbents and further utilization of waste biosorbents as additives in the production of building materials, which will significant contribute to the creation of low-waste technology and will ensure the sustainable development principles.

Lignocellulosic and cellulosic biosorbents were obtained from walnut shells by organosolv and oxidative-organosolv treatment as described in our previous paper. Initial material and biosorbents were used as additives in combination with cement. To study the physical and mechanical properties of building composites, the cement of I/500 type was used. For this purpose, cements preparation was done by mixing 
components in the ball mill for $20 \mathrm{~min}$. The cement samples were tested for normal density, coefficient of water removal, hardening time and compressive strength.

The structure as well as the sorption properties of materials based on biopolymers depend on the content of cellulose, lignin, hemicelluloses, extractives and mineral components, which define the ability of complex formation and cation exchange ability. Treatment of plant residues with acetic acid and with a mixture of acetic acid and hydrogen peroxide, under mentioned conditions, results in the formation of biosorbents of different composition. It is possible to vary the parameters of treatment depending on the intended application of the final product. The chemical composition of original walnut shells and obtained biosorbents of lignocellulosic and cellulosic types is shown in Fig. 7. As can be seen, the modification of the original material with acetic acid at the temperature $90{ }^{\circ} \mathrm{C}$ during $2 \mathrm{~h}$ leads to the partial degradation of low-molecular polysaccharides, the enrichment of the sorbent with lignin and the formation of lignocellulosic biosorbent is observed. The acidic treatment is also promoting the removal of mineral components from biomass.

Application of a mixture of acetic acid and hydrogen peroxide for the treatment of walnut shells promotes the removal of a larger portion of aromatic compounds, resulting in the formation of cellulosic biosorbent due to the presence of peracetic acid in solution at high temperatures, which is a strong delignifying reagent.

The results of the sorption study for $\mathrm{Cu}^{2+}$ ions from model solutions by the origin walnut shells and obtained biosorbents are represented in Fig. 8. Data analysis shows that the origin raw material has the highest sorption affinity for heavy metal. Treatment of shells with acetic acid and with a mixture of acetic acid and hydrogen peroxide results in a decrease in the sorption ability of biosorbents for the studied toxicant. 
a

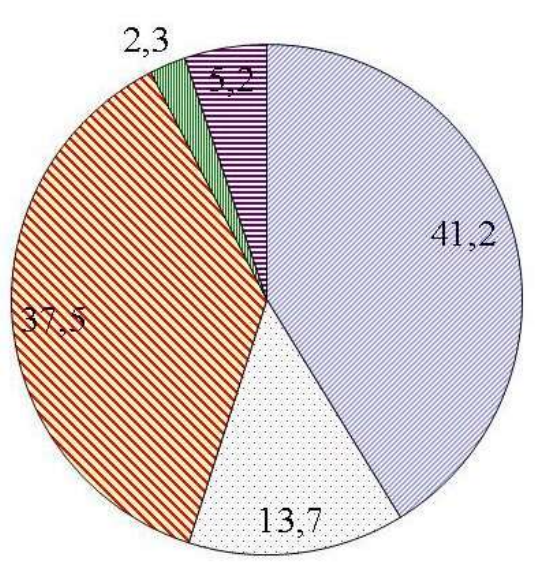

b

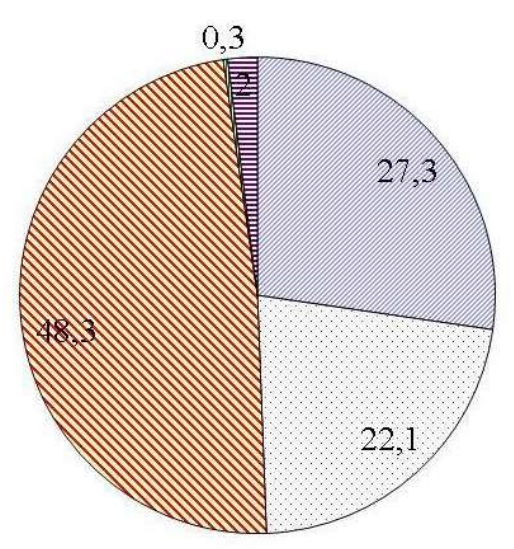

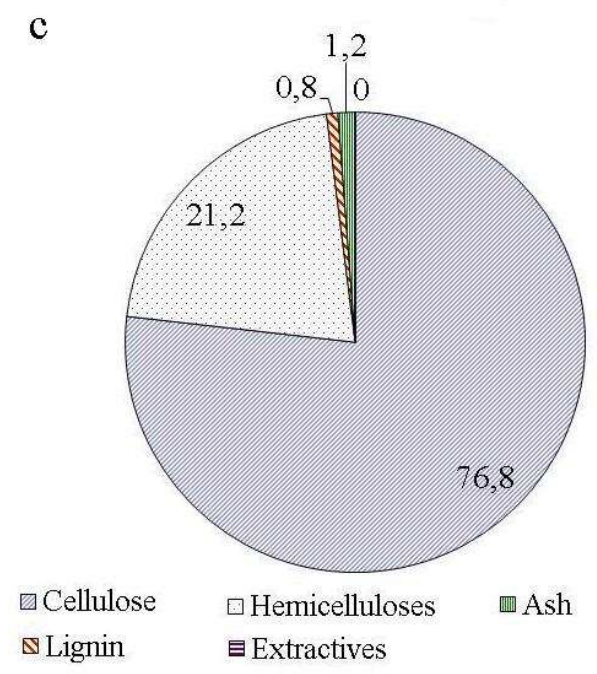

Figure 7. Chemical composition of original walnut shells (a), lignocellulosic

(b) and cellulosic (c) biosorbents from walnut shells

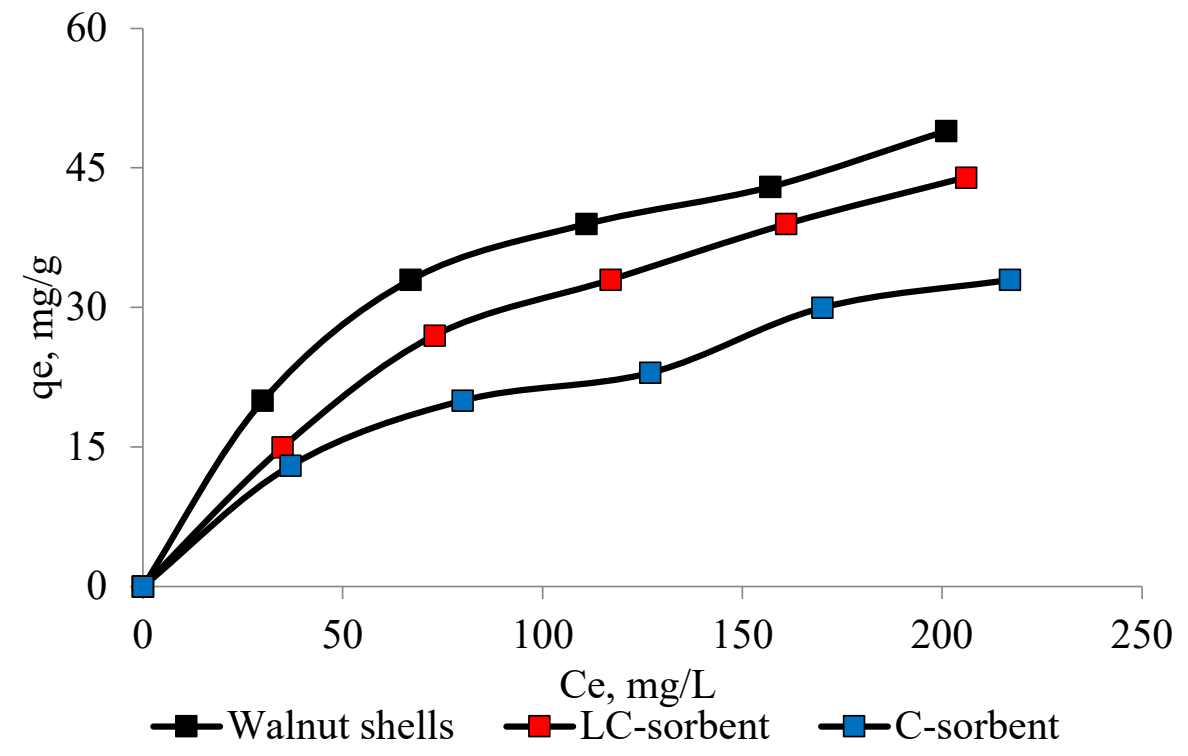

Figure 8. Sorption capacities towards $\mathrm{Cu}^{2+}$ from solutions of different concentrations 
It is obvious that the presence of different functional groups (hydroxyl, methoxyl, carbonyl, etc.) in plant raw materials results in specific sorption properties towards metal cations. In addition, tannins from origin raw material can bind heavy metal ions. Mineral components of the origin raw material, e.g. potassium, calcium, sodium, magnesium etc. also play a significant role in ion exchange processes.

The highest mineral content and high lignin content in the origin sample are responsible for the maximum sorption capacity for $\mathrm{Cu}^{2+}(49 \mathrm{mg} / \mathrm{g}$, respectively). Treatment of shell with acetic acid leads to a significant reduction in its minerals, but the relative content of lignin is slightly increased. Perhaps this causes a slight decrease of the sorption capacity of the lignocellulosic biosorbent toward the heavy metal cation and the maximum sorption capacities for $\mathrm{Cu}^{2+}$ was $44 \mathrm{mg} / \mathrm{g}$. The lowest sorption capacity corresponded to the cellulosic sorbent $(33 \mathrm{mg} / \mathrm{g}$ ), which had the minimum content of mineral compounds and lignin.

The linearized forms of the isotherms for sorption of $\mathrm{Cu}^{2+}$ on studied materials are presented in Fig. 9. The values of $\mathrm{R}^{2}$ for the Langmuir adsorption isotherm models even do not exceed 0.95 (Table 4). The data from Table 4 indicate that the adsorption processes fit well with the Freundlich model which describes physical and chemical sorption on heterogeneous surface.

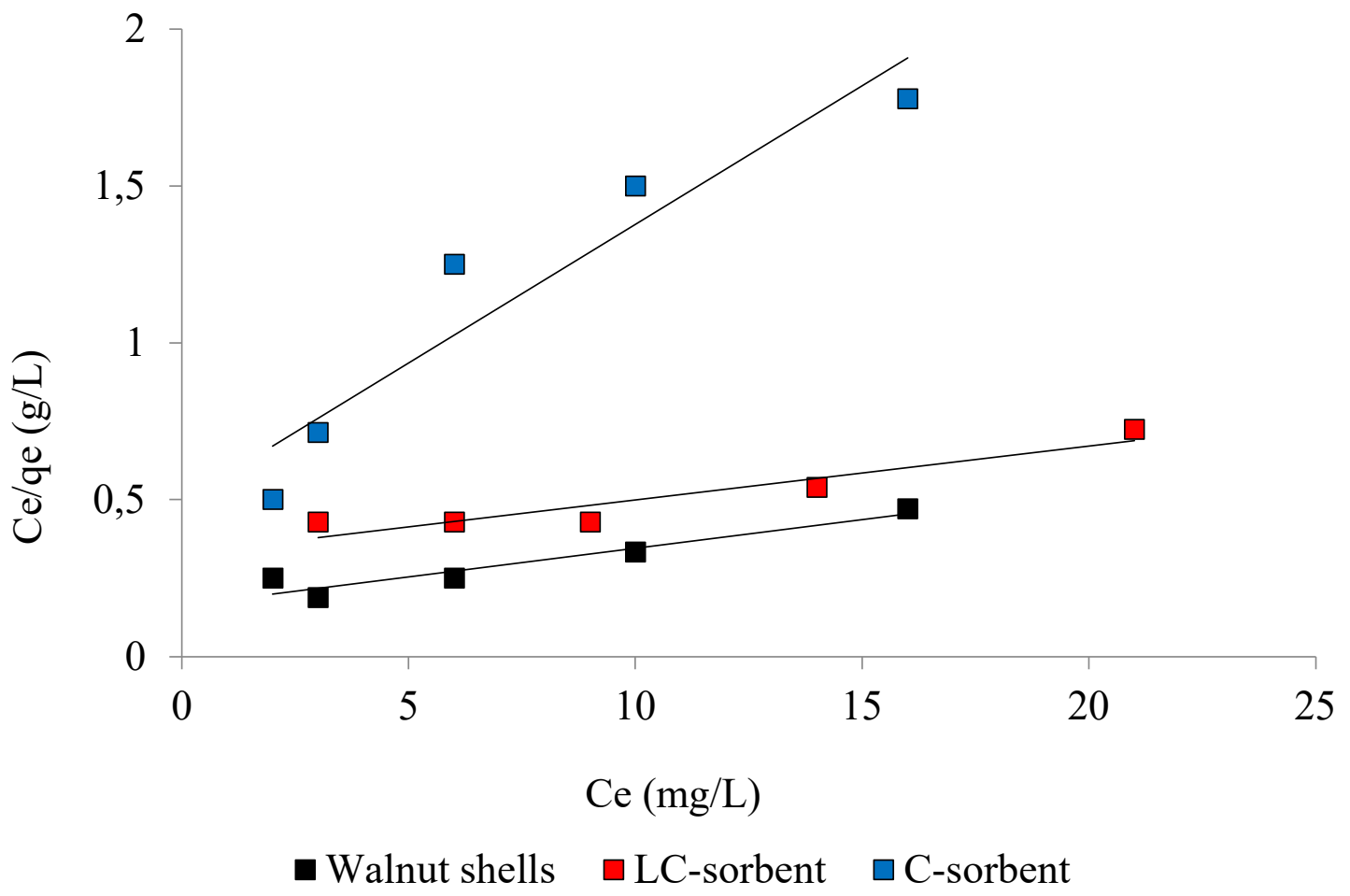




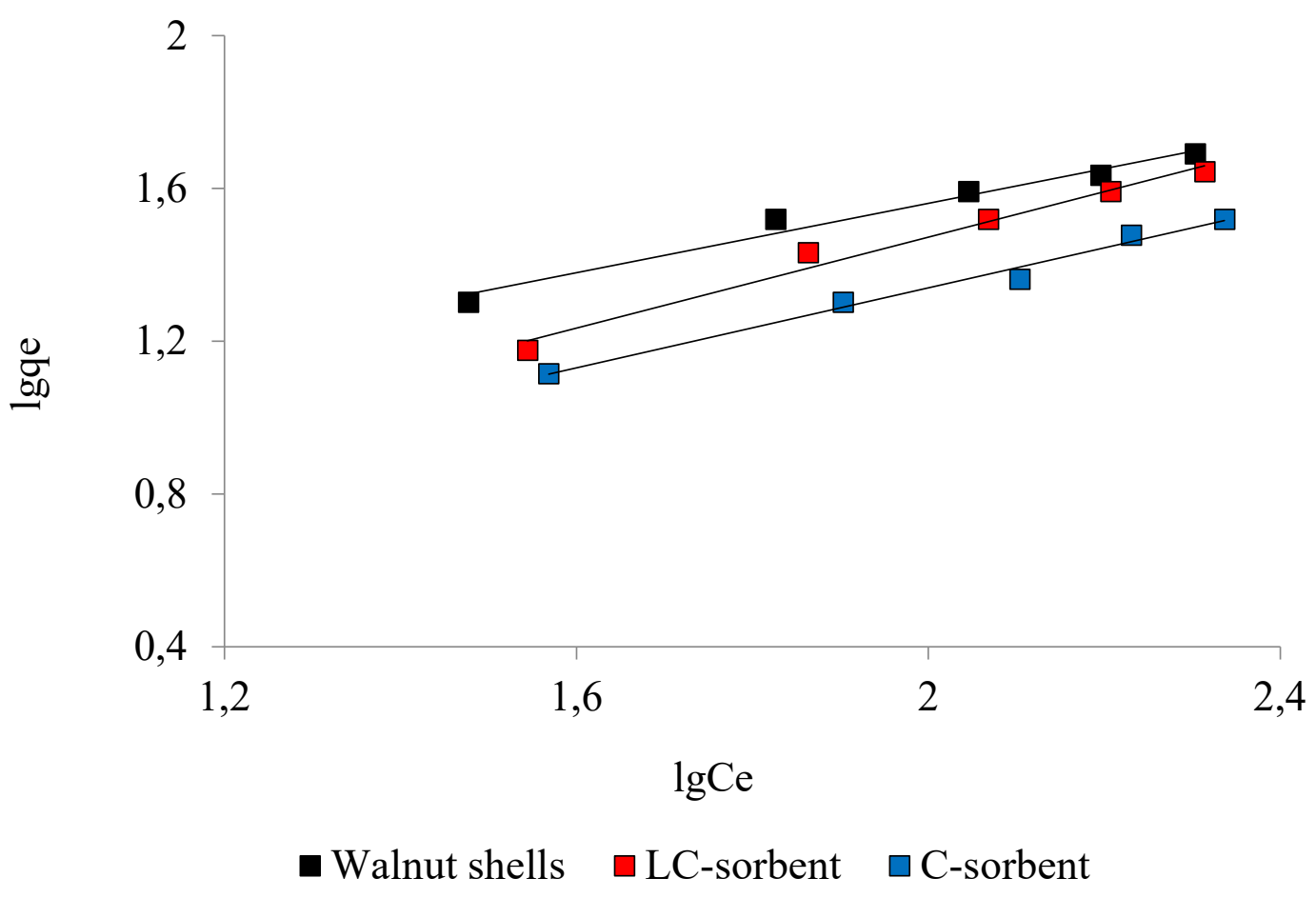

$\mathrm{b}$

Figure 9. Langmuir isotherms for $\mathrm{Cu}^{2+}$ (a) and Freundlich isotherms for $\mathrm{Cu}^{2+}$ (b)

Table 4

Parameters of adsorption isotherm models for $\mathrm{Fe}^{3+}$ and $\mathrm{Cu}^{2+}$

\begin{tabular}{|l|c|c|c|c|c|c|}
\hline \multirow{2}{*}{\multicolumn{1}{|c|}{ Sample }} & \multicolumn{3}{c|}{ Langmuir } & \multicolumn{3}{c|}{ Freundlich } \\
\cline { 2 - 8 } & $\mathrm{K}_{\mathrm{L},}$ & $\mathrm{Q}_{\mathrm{m},}$ & $\mathrm{R}^{2}$ & $\mathrm{~K}_{\mathrm{F},}$ & $\mathrm{n}$ & $\mathrm{R}^{2}$ \\
& $\mathrm{mg} / \mathrm{L}$ & $\mathrm{mg} / \mathrm{g}$ & & $\mathrm{L} / \mathrm{g}$ & & \\
\hline Walnut shells & $1.5 \cdot 10^{-2}$ & 63.3 & 0.9421 & 4.49 & 2.2 & 0.9751 \\
Lignocellulosic biosorbent & $8.8 \cdot 10^{-3}$ & 62.8 & 0.9422 & 1.91 & 1.7 & 0.9811 \\
Cellulosic biosorbent & $8.5 \cdot 10^{-3}$ & 49.3 & 0.9269 & 1.96 & 1.9 & 0.9856 \\
\hline
\end{tabular}

Due to high availability as well as to low cost of raw materials, such biosorbents can be easily utilized without regeneration. For nowadays, the effective methods of disposal of such spent biosorbents have not been developed. The content of cellulose, lignin, hemicelluloses, extractives and ash in biosorbnets affects the ability to swell in 
water solutions. This feature is very important and must be taken into account when developing disposal method.

According to State standard, it is allowed to introduced up to $5 \mathrm{wt}$ \% of additives to cement composition. Therefore, original walnut shells was introduced into the cement of type I-500-D, without any additives, in order to evaluate the effect of the walnut shells on the different properties of cement. The shells in a form of fine powder (particle size of 1-2 mm) were used for this purpose.

The influence of the original and modified walnut shells on the normal density of cement samples is given in Fig. 10. The results of the study indicate that original walnut shells act as a fine additive; the normal density is growth with the increase of shells content in the bulk of cement samples. The adding of $1 \%$ of walnut shells leads to insignificant change in the value of normal density. Further increase in shells content up to $5 \%$ results in growth of the parameter by 1.2 times. The change in the normal density is taking place due to the fact that more water is needed to form adsorption water coats around fine particles of the walnut shells. The higher shells content, the more water is consumed to obtain cement of normal density.

Fig. 11 shows that the hardening time is accelerated by 2.5 times at the content of walnut shells up to $5 \%$. The acceleration of hardening time is taking place due to the fact that the fine additive plays role of a thickener (similar to clay).

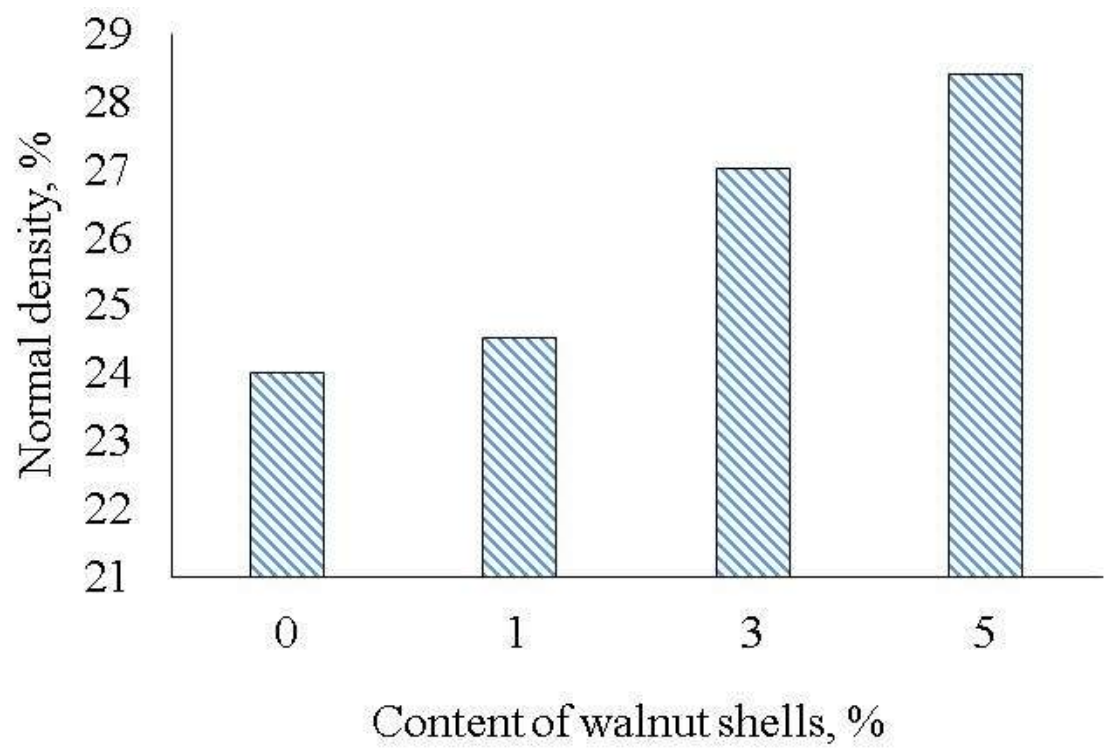

Figure 10. Effect of walnut shells content on normal density of cement 


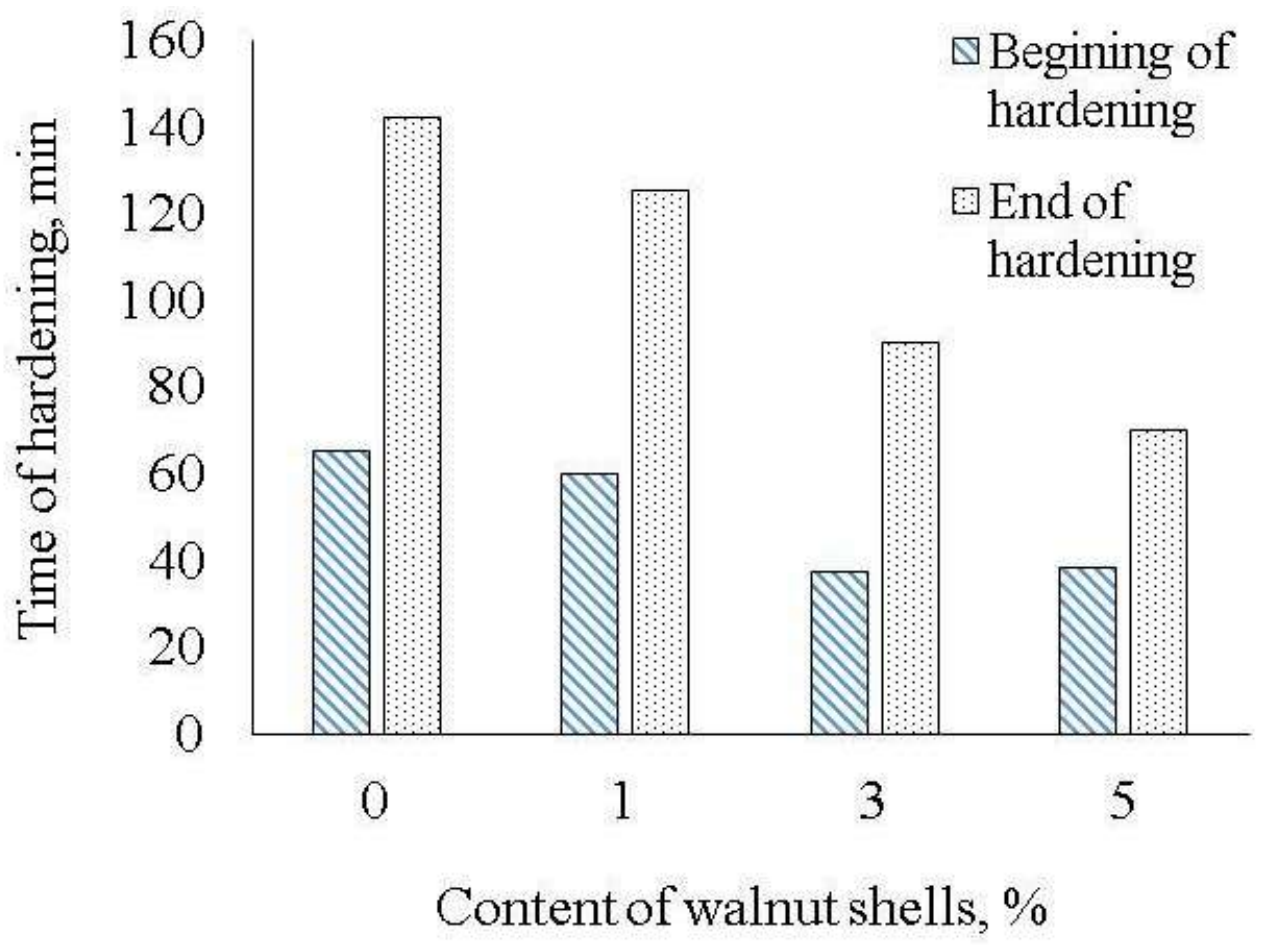

Figure 11. Effect of walnut shells content on hardening time of cement

The adding of walnut shells has a negative effect on the cement compressive strength as can be seen from Fig. 12 .

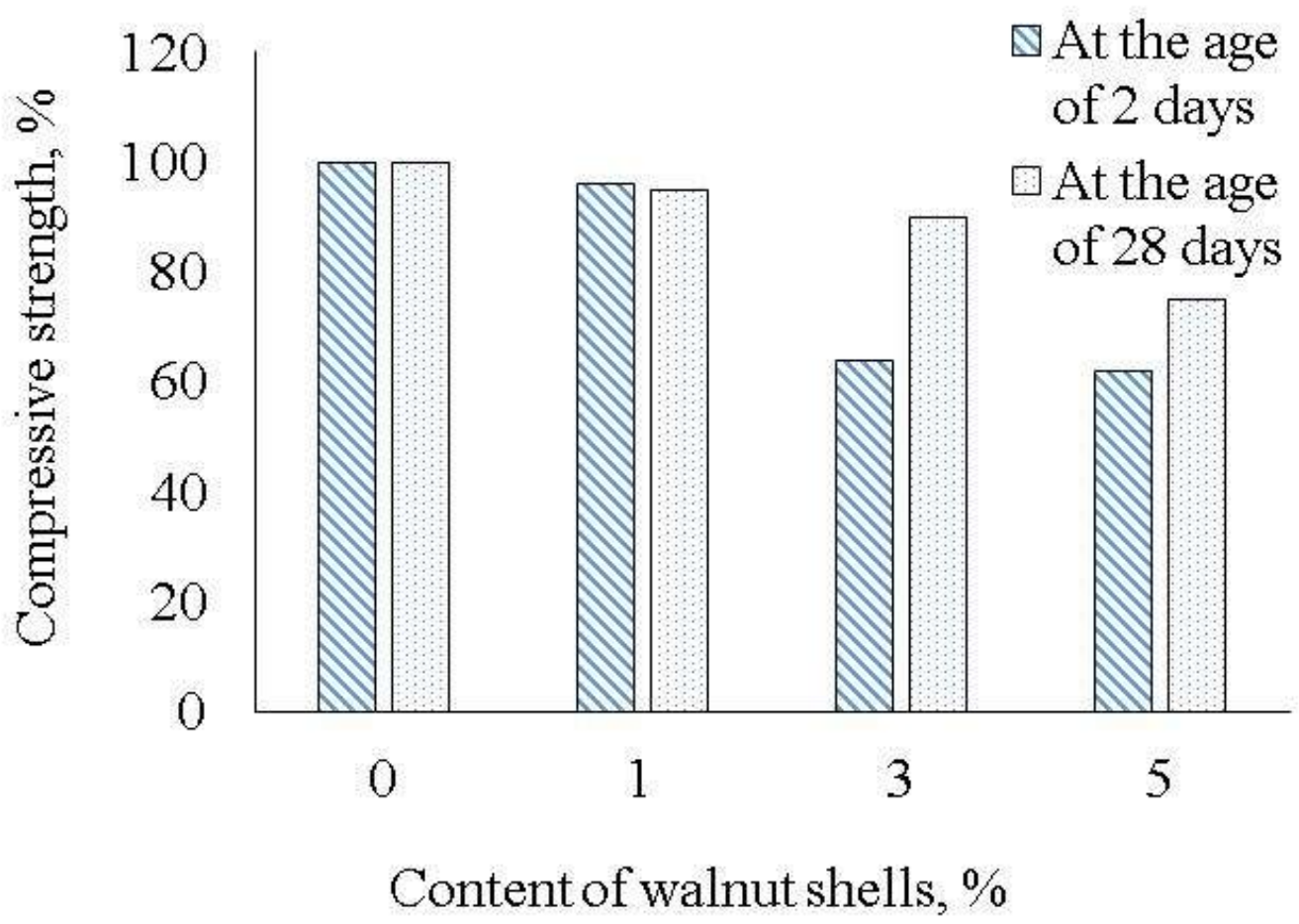

Figure 12. Effect of walnut shells content on cement compressive strength 
The strength of samples with the adding of shells after 2 days is less by $6-38 \%$, after 28 days is by $8-25 \%$.

Such results can be explained by the increased normal density of the cement. As the walnut shells do not effect to hydration and hydrolysis, and are unable to harden, the excess of water that is spent into the formation of adsorption coats around the shells particles and is not expended on the hydration of the clinker minerals and stays in the free state (early hardening period) or evaporates, thus resulting in the formation of pores in the cement stone (late hardening period).

The value of water removal coefficient insignificantly increases up to $6 \%$ with the increase of walnut shells content form 1 to $3 \%$ in cement samples, further increase in shells content has no effect on this parameter (Fig. 13).

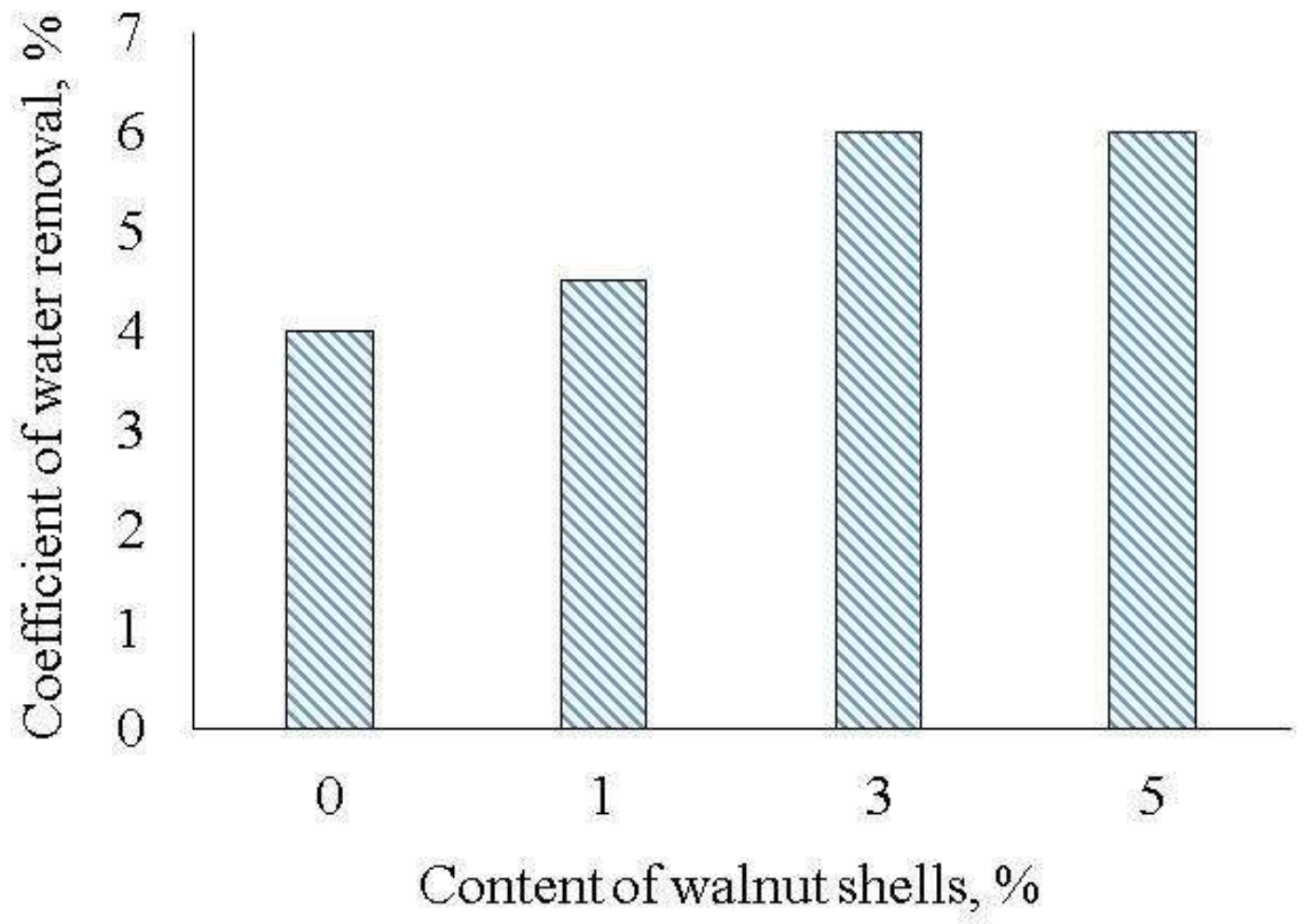

Figure 13. Effect of walnut shells content on water removal coefficient

Therefore, original walnut shells have a slight negative impact on the strength properties and water removal coefficient of cement. Thus it can be recommended for 
the application as an additive in the composition of cement in an amount of no more than $1 \%$.

The influence of the cellulosic and lignocellulosic biosorbents on the properties of cement was also studied. The introduction of $1 \%$ modified walnut shells to cement also leads to an increase in the value of normal density of the samples, as shown on Fig. 14. Cellulosic biosorbent has a greater effect on cement strength properties due to its fibrous structure and due to the presence of different oxygen-containing groups on its surface, which can participate in the formation of additional hydrogen bonds with molecules of water.

Both biosorbents of lignin and lignocellulosic types accelerate the time of hardening (Fig. 15), and the values are affected by the nature of the materials.

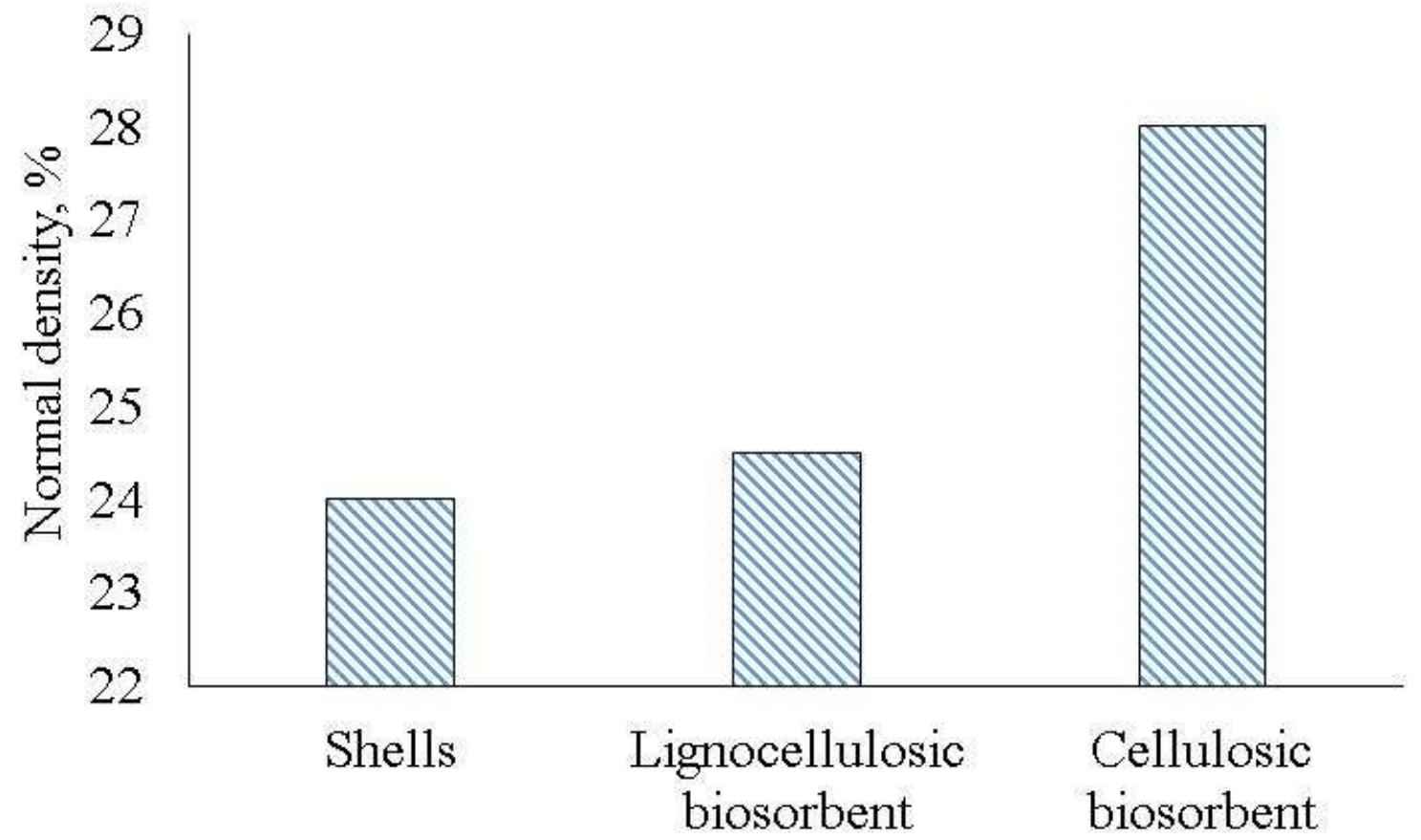

Figure 14. Effect of original material and biosorbents on cement normal density 


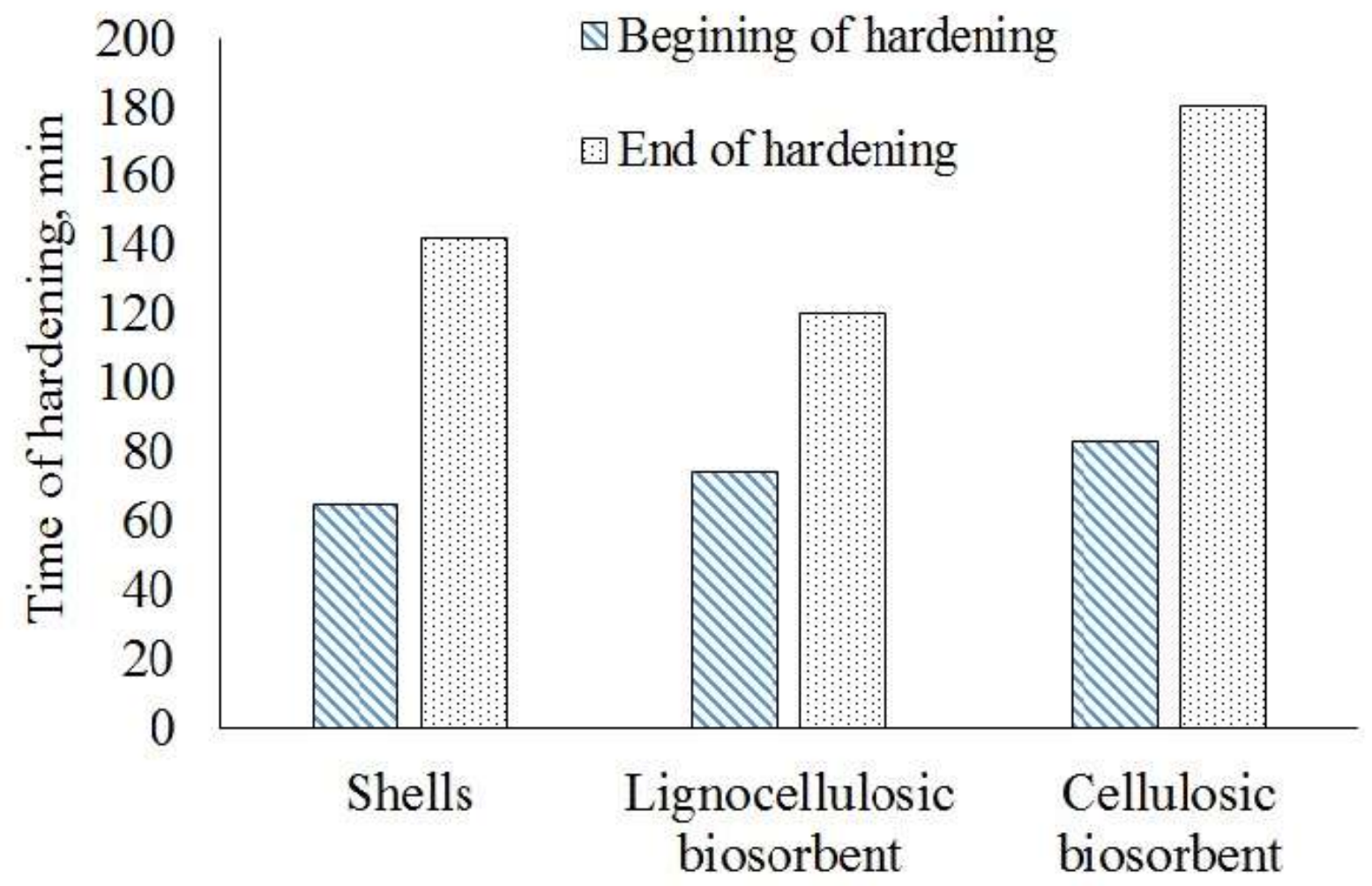

Figure 15. Effect of original material and biosorbents on cement hardening time

The higher lignin content in material, which is used as additive, the faster the hardening time due to the presence of methoxyl groups on its surface, which exhibit which are characterized by hydrophobic properties. Sample with higher cellulose content has the longest period of hardening time due to the ability to swell in water medium.

The results of the study of the compressive strength of cement with the natural plant materials in its composition are shown in Fig. 16. Cellulose in the composition of the modified biosorbents affects the slowing of hardening time, which is reflected in the strength properties of the cement samples at the age of 2 and 28 days. Adding of lignin-enriched biosorbent based on walnut shells to cement composition does not lead to a significant reduction of the mechanical and physical properties of the cement samples. Modified raw materials in the composition of the cement show different effects on the coefficient of water removal (Fig. 17). As can be seen, cellulosic biosorbent reduces the dehydration ability of cement sample. 


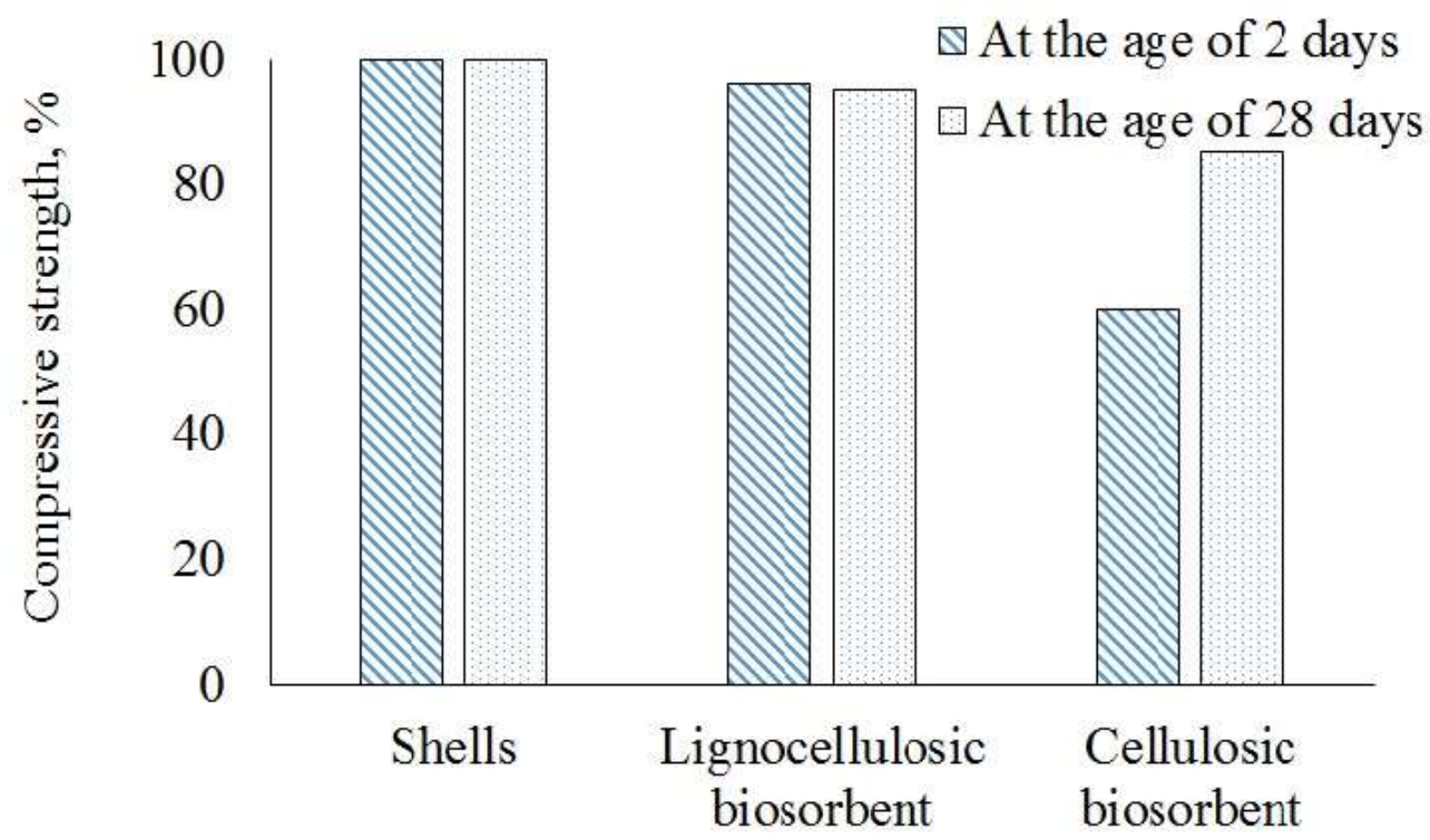

Figure 16. Effect of original material and biosorbents on compressive strength of cement

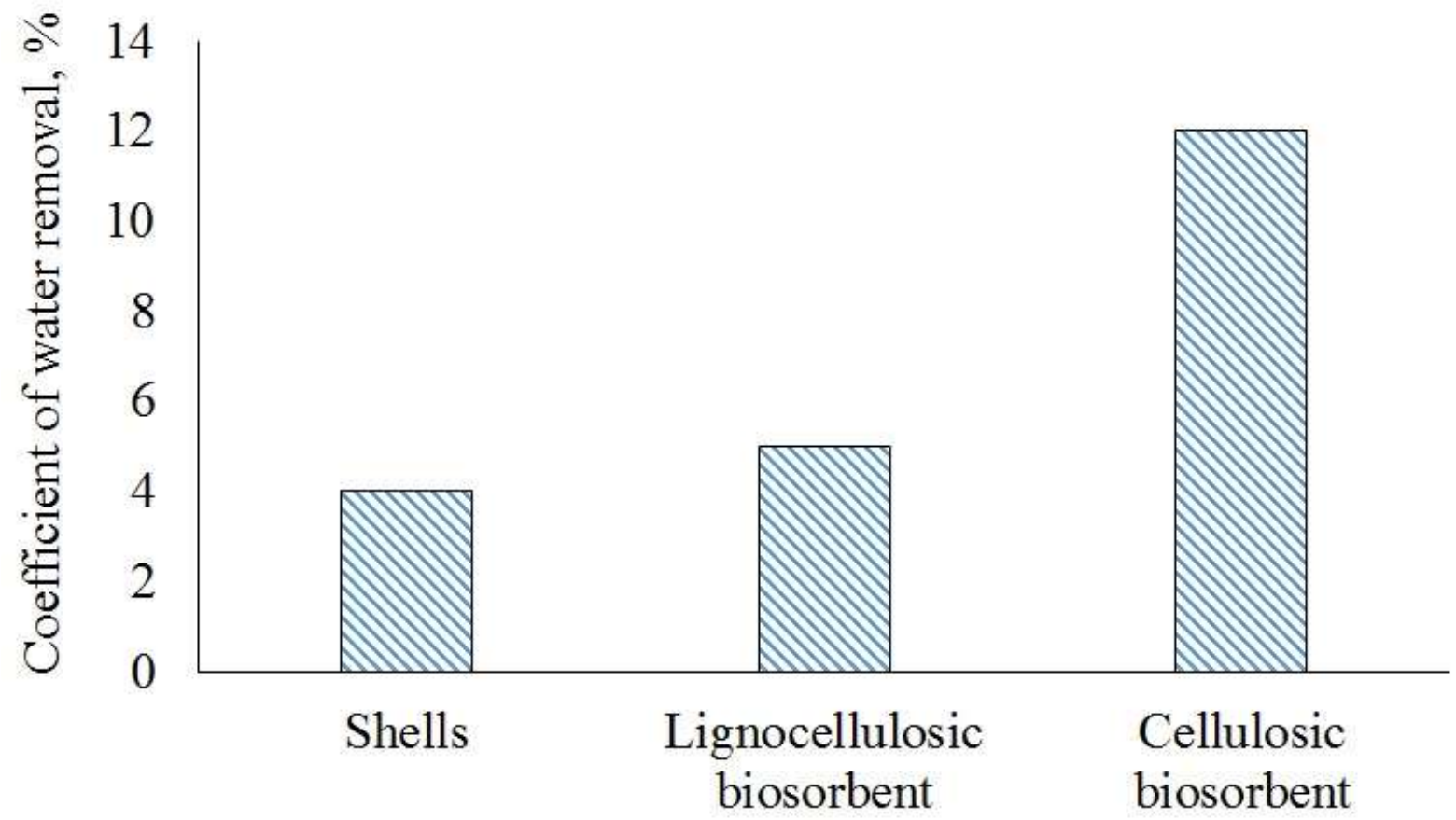

Figure 17. Effect of original material and biosorbents on coefficient of water removal of the cement 
So it can be concluded that biosorbent enrich in lignin similarly to original walnut shells can be recommended for use as an additive in an amount of no more than $1 \%$. However, at the same time cellulosic biosorbent has a negative effect on all cement mechanical and physical properties.

\section{Effective solution of the problem of utilization of plant wastes in the interests of ecology}

Due to the prolonged growth of anthropogenic impact, environmental pollution occurs all over the world. This leads to the pollution of all elements of biosphere atmosphere, lithosphere and hydrosphere. The content of organic substances, petroleum products and heavy metal ions exceeds the established standards not only in Ukraine. Heavy metals ions causes enormous damage to the environment, for instance, the functioning of activated sludge is disturbed, hydrobionts is significant damaged, ability of reservoirs for self-purification decrease.

In order to create a complex low-waste technology of wastewater demineralization and purification from heavy metal ions, the paper defines rational conditions for the utilization of waste biosorbents as additives in the production of building materials or fillers of polymeric materials used in construction.

The aim of the work is to study the effect of chemical modification of plant wastes of food industry with orthophosphoric acid into properties of biosorbents and to investigate the effect of spent biosorbents consumption on the properties of cement.

Grounded walnut shells (fraction with a particle size of 0.5-1.0 mm) with a content of cellulose $41.2 \%$, lignin $37.5 \%$, resins, fats, waxes $5.2 \%$, mineral components $2.3 \%$ were used as a raw material.

Modification of walnut shells was carried out by the partial hydrolysis with $\mathrm{H}_{3} \mathrm{PO}_{4}$ at $15-75 \mathrm{wt} . \%$, solid to liquid ratio was $1: 5$, at the temperature $100{ }^{\circ} \mathrm{C}$ for 60 $180 \mathrm{~min}$. By the end of the phosphorylation process, the samples of the lignocellulosic biosorbents were filtered, washed with distilled water to achieve neutral $\mathrm{pH}$ and airdried to a moisture content $6 \mathrm{wt} . \%$. 
The gravimetric method was used to determine the biosorbents yield. The absorption capacity of the original material and modified shells towards methylene blue was determined in static conditions using a model solution with a cationic dye concentration $100 \mathrm{mg} / \mathrm{l}$. The process duration was $24 \mathrm{~h}$. The initial and equilibrium concentrations of sorbate in solutions were determined by spectrophotometric method using a SPEKOL 11 spectrophotometer. The wavelength for dye was $630 \mathrm{~nm}$.

Studies of ion-exchange properties (static exchange capacity) of original and phosphorylated shells were determined by the amount of $\mathrm{Na}^{+}$uptake from $0.1 \mathrm{~N} \mathrm{NaOH}$ solution during $24 \mathrm{~h}$.

Original and modified shells were also applied as additives in the composition of cement. To investigate the effect of phosphorylated biosorbents present in the composition of cement on its different properties, the I/500 type cement was used for this purpose.

The mineralogical composition of the cement was the following, wt. \%: $\mathrm{C}_{3} \mathrm{~S}-$ 57.10, $\mathrm{C}_{2} \mathrm{~S}-21.27, \mathrm{C}_{3} \mathrm{~A}-6.87, \mathrm{C}_{4} \mathrm{AF}-12.19$. Samples preparation was carried out by mixing all components in the ball mill for $20 \mathrm{~min}$. The cement samples than were tested for hardening time, normal density, compressive strength.

Influence of $\mathrm{H}_{3} \mathrm{PO}_{4}$ concentration and time of phosphorylation on biosorbents properties

Table 5 presences the results of the investigation of sorption properties of phosphorylated biosorbents namely the efficiency of methylene blue removal from the water solution and the static exchange capacity towards $\mathrm{Na}^{+}$of original and modified materials depending on the time of phosphorylation with $\mathrm{H}_{3} \mathrm{PO}_{4}$. 
Table 5.

Biosorbents yields and sorption properties

\begin{tabular}{|c|c|c|c|c|}
\hline \multirow[b]{2}{*}{$\begin{array}{c}\mathrm{H}_{3} \mathrm{PO}_{4} \\
\text { concentration, } \\
\text { wt. } \%\end{array}$} & \multirow[b]{2}{*}{$\begin{array}{c}\text { Time of } \\
\text { modification, } \\
\mathrm{h}\end{array}$} & \multicolumn{3}{|c|}{ Biosorbents parameteres } \\
\hline & & $\begin{array}{c}\text { Yield, } \\
\%\end{array}$ & $\begin{array}{c}\text { Static exchange } \\
\text { capacity for } \\
\mathrm{Na}^{+}, \\
\mathrm{mg-eq} / \mathrm{g}\end{array}$ & $\begin{array}{c}\text { Efficiency of } \\
\text { methylene blue } \\
\text { uptake, \% }\end{array}$ \\
\hline- & - & - & 1.48 & 39.2 \\
\hline \multirow{3}{*}{30} & 60 & 80.0 & 2.49 & 51.3 \\
\hline & 120 & 78.7 & 2.78 & 53.0 \\
\hline & 180 & 70.4 & 2.94 & 57.5 \\
\hline \multirow{3}{*}{50} & 60 & 77.1 & 2.94 & 55.3 \\
\hline & 120 & 70.6 & 3.29 & 69.3 \\
\hline & 180 & 65.6 & 3.33 & 80.1 \\
\hline \multirow{3}{*}{75} & 60 & 70.9 & 2.99 & 58.2 \\
\hline & 120 & 63.1 & 3.36 & 71.6 \\
\hline & 180 & 58.8 & 3.37 & 79.9 \\
\hline
\end{tabular}

The results of the experiments show that the parameters of the modification significantly affect all biosorbents properties.

The increase in concentration of acid from 30 to $75 \%$ promotes a decrease in the yield of the biosorbents. The same is observed with increasing in modification time. In spite of this, the sorption ability was improved as the static exchange capacity towards $\mathrm{Na}^{+}$and efficiency of methylene blue sorption increase throughout the investigated range. This can be explained by the fact that during the process of phosphorylation the removal from the plant raw materials of organic and inorganic substances, depolymerization of polysaccharide components, which leads to the formation of more porous structure in lignocellulosic products, take place. 
The sorption of the cationic dye on such biosorbents occurs both due to physical adsorption and by the mechanisms of chemical uptake with the participation of functional groups of the modified material.

The technological scheme for water treatment with the application of biosorbents

On the basis of the given results, a complex technology of water demineralization can be proposed. The scheme for the efficient wastewater treatment from heavy metal ions using biosorbents based on walnut shells is presented in Fig. 18.

Wastewater, which contains heavy metal ions, enters the reservoir 1 , where, in case of presence of divalent iron ions, the air is supplied by the compressor. During intensive aeration, the oxidation of ferrous iron to form insoluble ferric hydroxide occurs, which is than separated on a mechanical filter 2 . From the mixer 3 wastewater enters the chamber for biosorption purification 4, where the special system 11 doses the required amount of biosorbent. The process is carried out at a constant stirring, which increases the efficiency of sorption. The treated water is separated from the waste sorbent in the separator 5 . The spent biosorbent is dehydrated on the filter press 8 and then dried in the dryer 9 . The dry biosorbent is then can be utilized. 


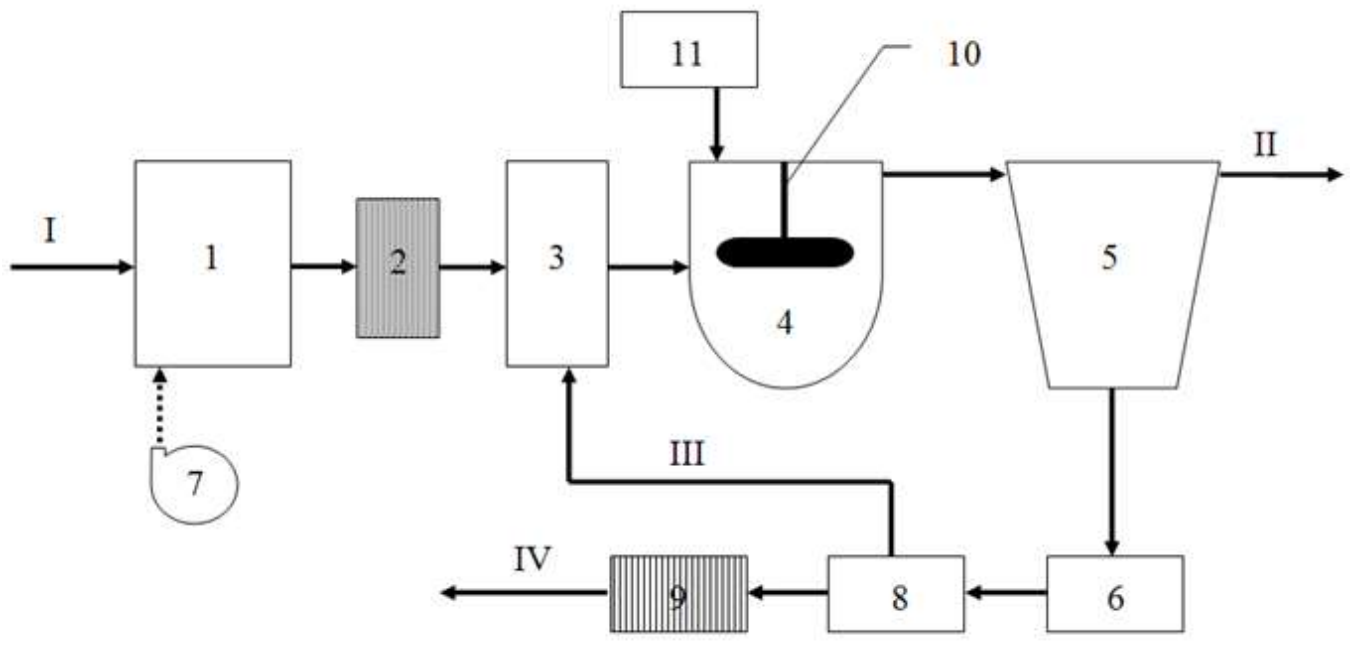

Figure 18. Technological scheme for wastewater treatment from heavy metal ions using sorbents based on walnut shells: I - wastewater; II - treated water; III filtrate from the filter press; IV - dry biosorbent for utilization

1 - collecting tank; 2 - mechanical filter; 3 - mixer; 4 - chamber for sorption purification; 5 - separator for separation of waste sorbent; 6 - waste sorbent collector; 7 - compressor for blowing air; 8 - filter press; 9 - dryer for waste sorbent; 10 - mixer; 11 - system of dosing and delivery of biosorbent

\section{Application of waste biosorbents as additives in the cement production}

When evaluating the impact of original walnut shell on the physical and chemical properties of cement, it was established that original walnut shells play the role of a fine additive, which increase the normal density (on 6-19\%) and accelerates the hardening time (2.0-2.5 times) as can be seen from Table 6 . The increase in normal density takes place due to the fact that more water is needed to form adsorption water shells around fine particles of plant material. The higher the content of the shell, the more water is consumed to obtain a cement of normal density. The acceleration of hardening time takes place also due to the fact that the fine additive acts as a thickener (similar to clay). 
SCIENTIFIC FOUNDATIONS OF SOLVING ENGINEERING TASKS AND PROBLEMS

Table 6.

The effect of walnut shawls content in the composition of cement on its

properties

\begin{tabular}{|c|c|c|c|c|c|c|}
\hline \multirow{2}{*}{$\begin{array}{l}\text { Walnut } \\
\text { shells } \\
\text { content, } \\
\text { wt. \% }\end{array}$} & \multirow[b]{2}{*}{$\begin{array}{c}\text { Normal } \\
\text { density, } \\
\%\end{array}$} & \multicolumn{2}{|c|}{ Hardening time, $\min$} & \multicolumn{2}{|c|}{ Compressive strength, $\%$} & \multirow{2}{*}{$\begin{array}{c}\text { Coefficient } \\
\text { of water } \\
\text { removal, } \\
\%\end{array}$} \\
\hline & & begging & end & $\begin{array}{l}\text { at the age } \\
\text { of } 2 \text { days }\end{array}$ & $\begin{array}{c}\text { at the age of } \\
28 \text { days }\end{array}$ & \\
\hline- & 24.0 & 62 & 140 & 100 & 100 & 4.1 \\
\hline 1 & 24.5 & 60 & 130 & 98 & 98 & 4.5 \\
\hline 3 & 27.1 & 45 & 90 & 68 & 95 & 6.0 \\
\hline 5 & 28.4 & 40 & 75 & 65 & 80 & 6.0 \\
\hline
\end{tabular}

The compressive strength of cement decreases with the increase in walnut shells content but the effect is a minor. That can be explained by the increased normal density of the cement. The coefficient of water removal also increases, but not significantly (from $4 \%$ to $6 \%$ ), and the increase in the content of the shells above 3\% doesn't lead to any changes in mentioned values.

The effect of the adding of $1.5 \%$ of modified walnut shell on the physical and chemical properties of cement is shown in Fig. 19. The samples of biosorbents obtained during walnut shells modification with acid of different concentration during 120 min, were chosen for further investigations.

Data in Fig. 19 clearly show that the impact of phosphorylated walnut shells onto normal density is quite insignificant if compared to original material. It is also obvious, that acid modification leads to decrease in the beginning of hardening of cement due to the higher lignin content. Compressive strength increases in all cases due to the fact that lignin shows quite good binding properties. The water removal coefficient of cement changes insignificantly in comparison with initial material.

Thus, taking into account positive effect of adding the phosphorylated shells on the physicochemical properties of the cement, it can be recommended to use them for 
the fact of development of effective method of its utilization through the application in cement production in quantity of 1-3\%.

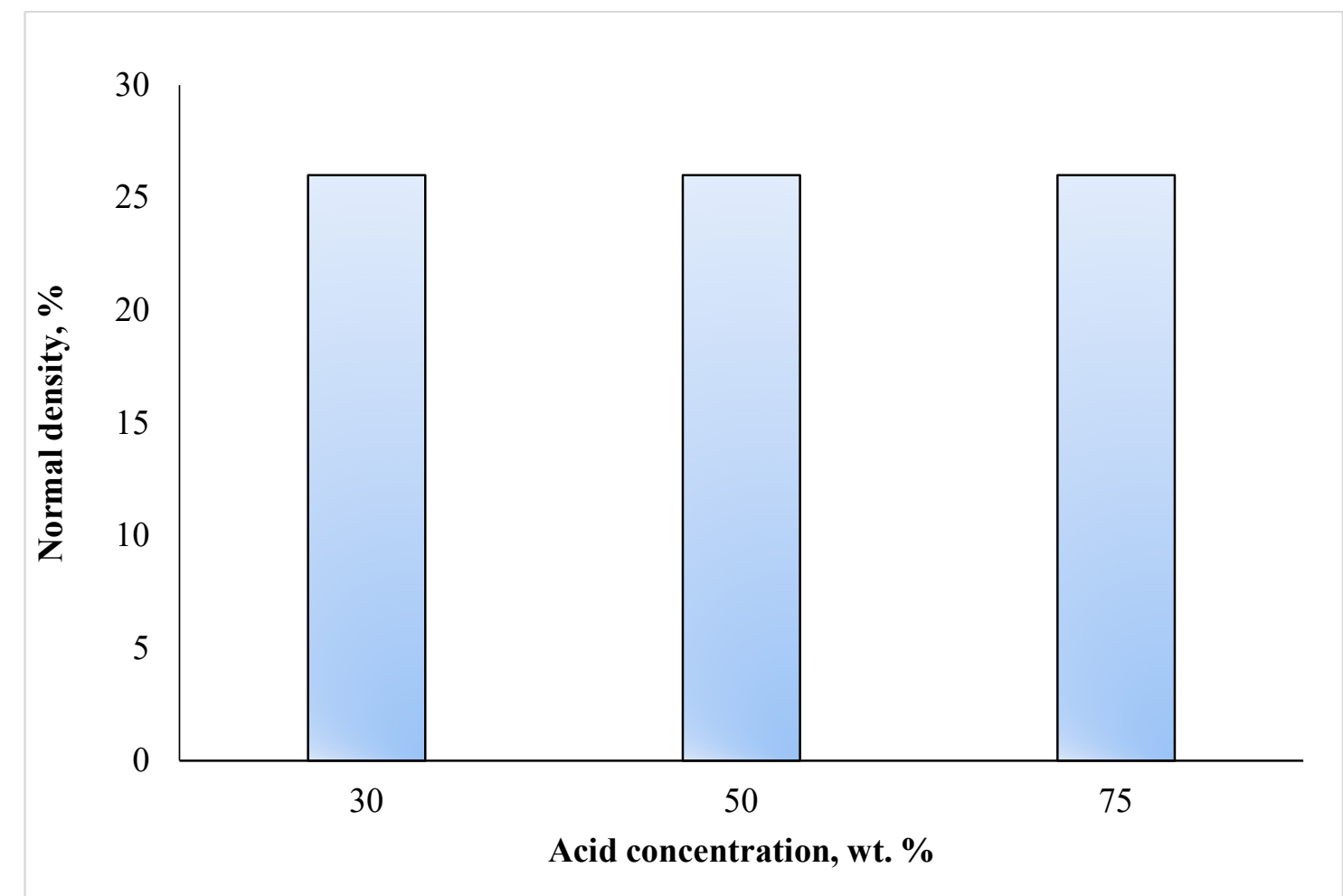

a

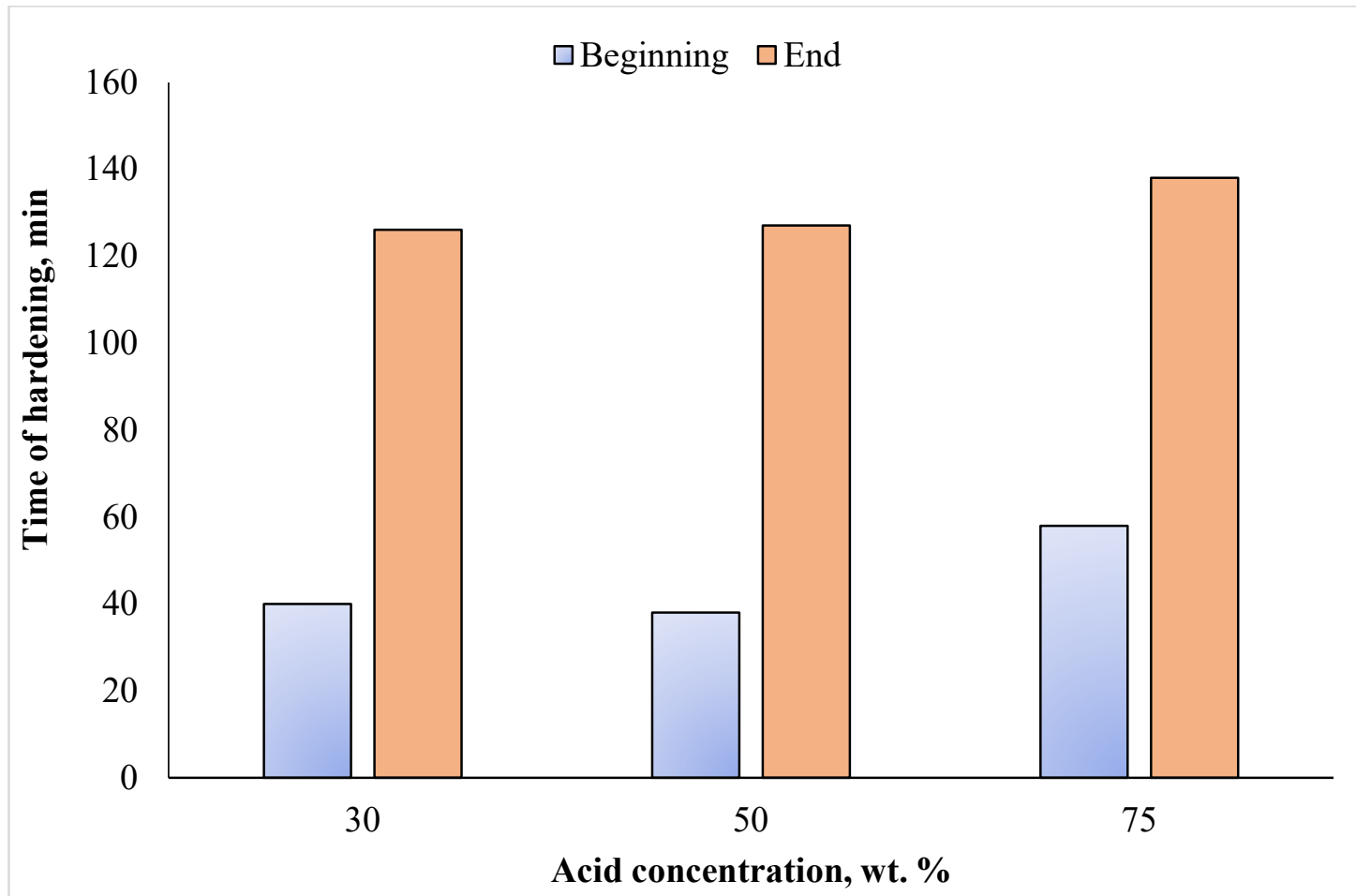

b 


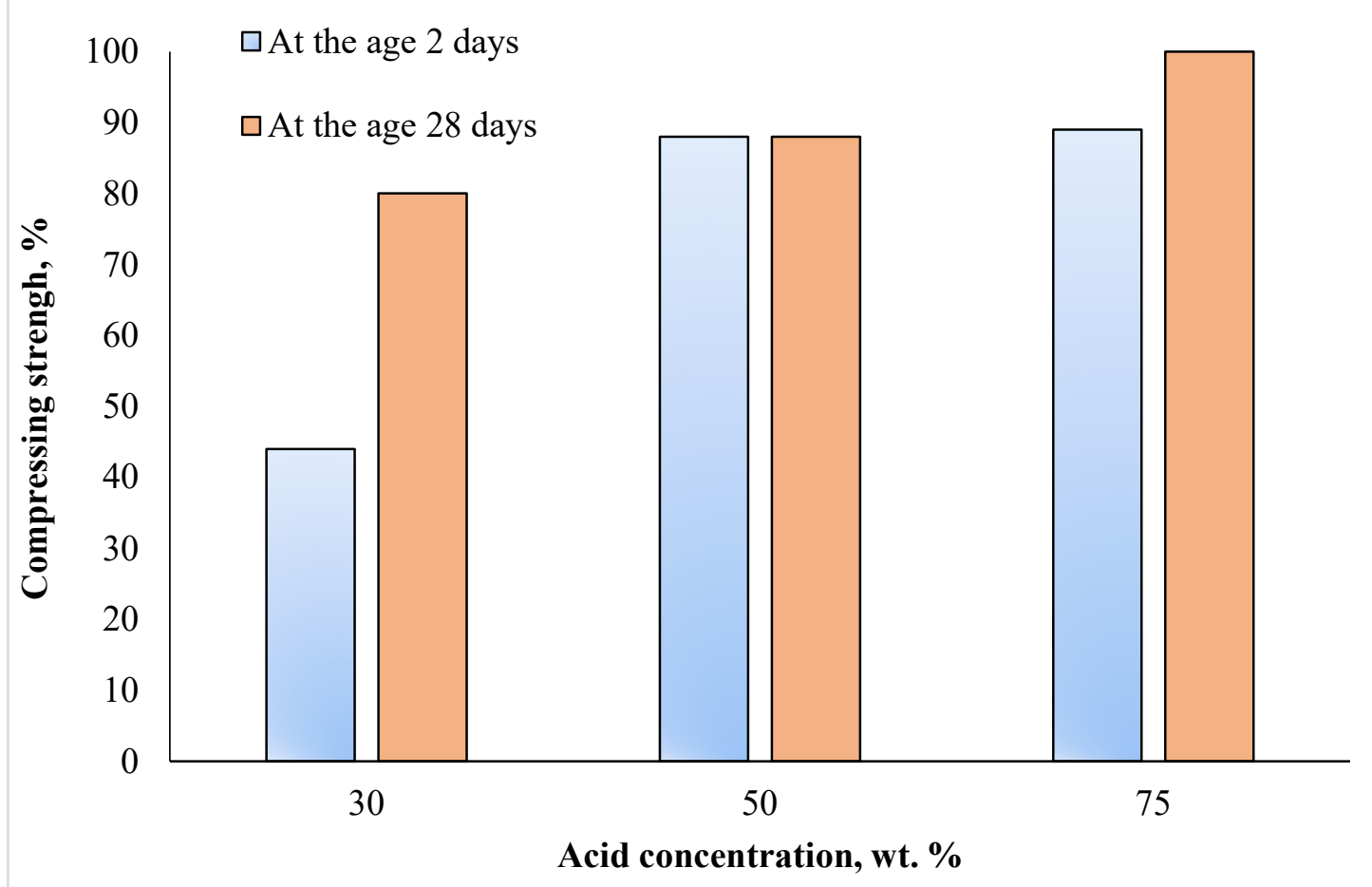

c

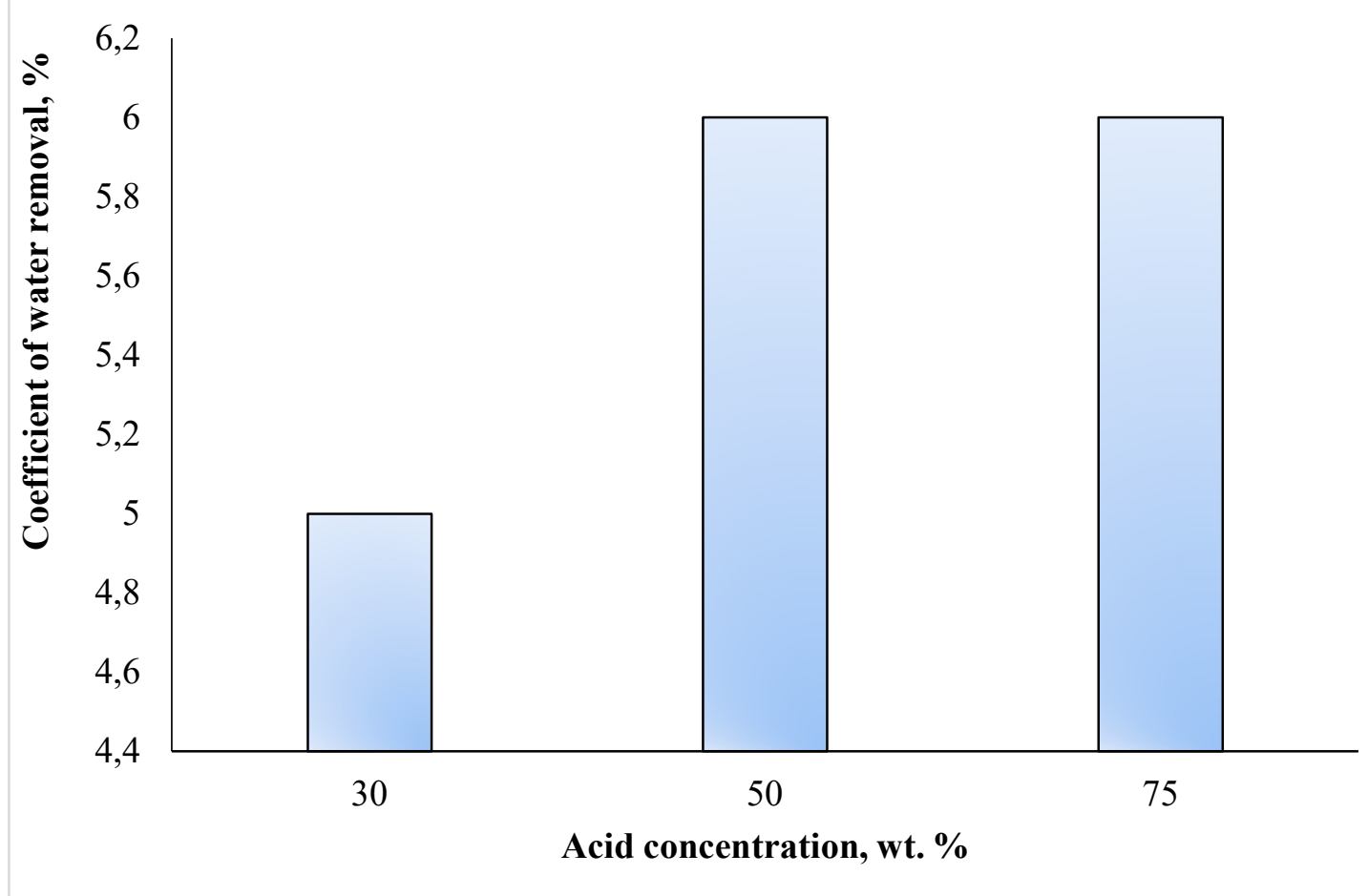

d

Figure 19. Physical and mechanical properties of cement with different content of modified walnut shells $1.5 \%$ : a - normal density; $\mathrm{b}$ - hardening time; $\mathrm{c}$ compressive strength; $d$ - coefficient of water removal 


\section{Conclusions}

1. Copper hydroxide, which is formed during the purification of water, was utilized as an additive in cement of I-500 type. The sludge was added into the cement composition and their effect was evaluated according to the vlues of normal density, strength, hardening time, and water removal with respect to the methods for small samples. The precipitates based on hydroxides increase the strength of cement and do not affect water removal ability, so they can be recommended for the use in cements as chemical additives. The economically feasible technology of complex purification of aqueous solutions from copper ions using reagent methods with utilization of the formed precipitates as a part of cement was developed.

2. The possibility of utilization of different biosorbents in the composition of cement was studied. Obtained results show limited ability of the application of original and modified walnut shells in the composition of cement. Original walnut shell acts as a fine additive, which increase the normal density and accelerates the hardening time. The compression strength of the studied samples is slightly decrease. Results have shown that enriched with lignin biosorbent in the composition of cement has a little effect on the physical and mechanical properties. The utilization of cellulosic biosorbents by the use as additives in production of cement cannot be recommended as the physical and mechanical properties were reduced significantly.

3. The efficiency of walnut shells modification with $\mathrm{H}_{3} \mathrm{PO}_{4}$ at different concentrations was studied. It was find out that sorption properties of obtained materials greatly depend on the parameters modification process. The technological scheme for wastewater treatment from ions of heavy metal with the application of biosorbents and the way of waste biosorbents utilization was proposed. It was also found out that the shells act as a fine additive, that increase the normal density and accelerates the hardening time of cement. The compressive strength of the cement samples with the application of lignocellulosic biosorbents decreases slightly. Result show that inorganic acid, which has been used for modification, leads to increase in biosorbent sorption capacity and has little adverse effect on the hardening time of cement. 